\title{
Diagnostic calibration of a hydrological model in an alpine area by hydrograph partitioning
}

\section{Z. H. $\mathrm{He}^{1}$, F. Q. $\operatorname{Tian}^{1}$, H. V. Gupta ${ }^{2}$, H. C. $\mathrm{Hu}^{1}$, and H. P. Hu ${ }^{1}$}

${ }^{1}$ State Key Laboratory of Hydroscience and Engineering, Department of Hydraulic Engineering, Tsinghua University, Beijing, 100084, China

${ }^{2}$ Department of Hydrology and Water Resources, The University of Arizona, Tucson, Arizona, 85721, USA

Received: 27 October 2014 - Accepted: 23 November 2014 - Published: 9 December 2014 Correspondence to: F. Q. Tian (tianfq@tsinghua.edu.cn)

Published by Copernicus Publications on behalf of the European Geosciences Union.

Diagnostic

calibration of

a hydrological model

in an alpine area

Z. H. He et al.

Title Page

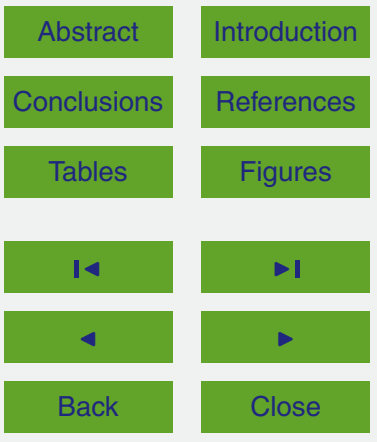

Full Screen / Esc

Printer-friendly Version

Interactive Discussion 


\section{Abstract}

Hydrological modeling can exploit informative signatures extracted from long time sequences of observed streamflow for parameter calibration and model diagnosis. In this study we explore the diagnostic potential of hydrograph partitioning for model calibra5 tion in alpine areas, where meltwater from snow and glaciers are important sources for river runoff (in addition to rainwater). We propose an index-based method to partition the hydrograph according to dominant runoff water sources, and a diagnostic approach to calibrate an alpine hydrological model. First, by accounting for the seasonal variability of precipitation and the altitudinal variability of temperature and snow/glacier coverage, we develop a set of indices to indicate the daily status of runoff generation from each type of water source (i.e. glacier meltwater, snow meltwater, rainwater, and groundwater). Second, these indices are used to partition a hydrograph into four parts associated with four different combinations of dominant water sources (i.e. groundwater, groundwater + snow meltwater, groundwater + snow meltwater + glacier meltwater, groundwater + snow meltwater + glacier meltwater + rainwater). Third, the hydrological model parameters are grouped by the associated runoff generation mechanism, and each group is calibrated to match the corresponding hydrograph partition in a stepwise and iterative manner. Similar to use of the regime curve to diagnose seasonality of streamflow, the hydrograph partitioning curve based on a dominant runoff water source (more briefly called the partitioning curve, not necessarily continuous) can serve as a diagnostic signature that helps relate model performance to model components. The proposed methods are demonstrated via application of a semi-distributed hydrological model (THREW) to the Tailan River basin $\left(1324 \mathrm{~km}^{2}\right)$ in the Tianshan Mountain of China.

\section{HESSD}

$11,13385-13441,2014$
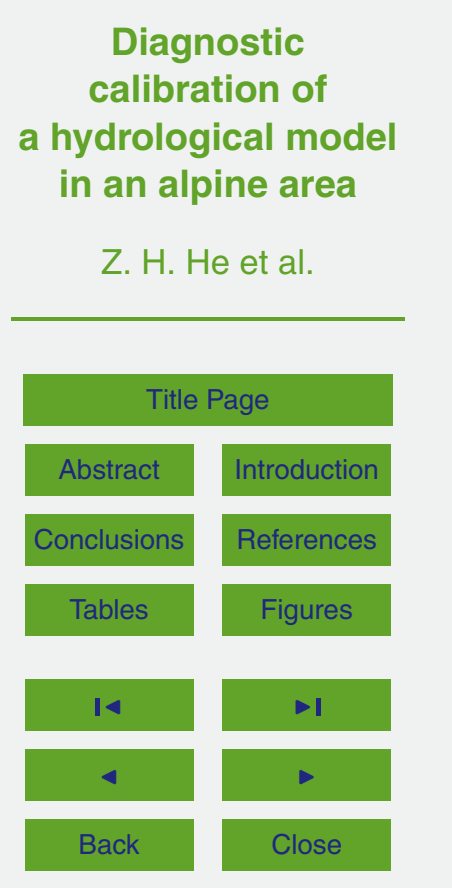

Full Screen / Esc

Printer-friendly Version

Interactive Discussion 


\section{Introduction}

\subsection{Background}

Parameter calibration has been singled out as one of the major issues in the application of hydrological models (Johnston and Pilgrim, 1976; Gupta and Sorooshian, 1983;

5 Beven and Binley, 1992; Boyle et al., 2000). Commonly, one or more objective functions are selected as criteria to evaluate the similarity between observed and simulated hydrographs (Nash and Sutcliffe, 1970; Brazil, 1989; Gupta et al., 1998; van Griensven and Bauwens, 2003). As model complexity increases, parameter dimensionality also increases significantly, which makes it much more difficult to calibrate model parameters manually. For this reason, automatic calibration procedures have been developed to identify the optimal parameter set (Gupta and Sorooshian, 1985; Gan and Biftu, 1996; Vrugt et al, 2003a, b). However, due to limitations in process understanding and measurement technologies, one can find different parameter sets within a chosen space that may acceptably reproduce the observed aspects of the catchment system (Sorooshian and Gupta, 1983; Beven and Freer, 2001). This phenomenon, which has been called "equifinality", causes uncertainty in simulation and prediction (Duan et al., 1992; Beven, 1993, 1996), and highlights the need for methods that are powerful enough to "diagnostically" evaluate and correct models, i.e. that are capable of indicating to what degree a realistic representation of the real world has been achieved and pointing towards how the model should be improved (Spear and Hornberger, 1980; Gupta et al., 1998, 2008).

Traditional regression-based model evaluation strategies (e.g. based on the use of Mean Squared Error or Nash Sutcliffe Efficiency as performance criteria) are demonstrably poor in their ability to identify the roles of various model components or pa-
HESSD

$11,13385-13441,2014$

Diagnostic

calibration of

a hydrological model

in an alpine area

Z. H. He et al.

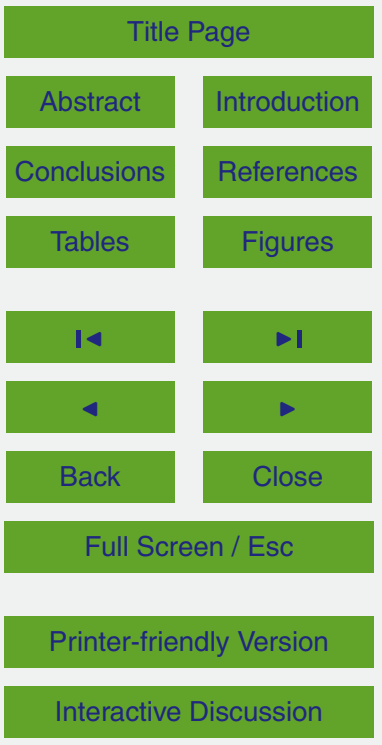
Gupta et al., 2008; Yilmaz et al., 2008; Hingray et al., 2010), which is due in part to the loss of meaningful information when projecting from the high dimension of the data set (like hydrograph) down to the low (often one) dimension of the measure (Yilmaz et al., 
2008; Gupta et al., 2009). A diagnostic evaluation method should match the number of unknowns (parameters) with the number of pieces of information by making use of multiple measures of model performance (Gupta et al., 1998, 2008, 2009; Yilmaz et al., 2008). One way to exploit hydrological information is to analyze the spatiotemporal 5 characteristics of hydrological variables that can be related to specific hydrological processes in the form of "signature indices" (Richter et al., 1996; Sivapalan et al., 2003; Gupta et al 2008; Yilmaz et al., 2008). Ideally, a "signature" should represent some "invariant" property of the system, be readily identifiable from available data, directly reflect some system function, and be maximally related to some "structure" or "param10 eter" in the model.

Attention to hydrological signatures, therefore, constitutes the natural basis for model diagnosis (Gupta et al., 2008). Placed in this context, the body of literature on the topic is indeed large. Jothityangkoon et al. (2001) proposed a downward approach to evaluate the model's performance against appropriate signatures at progressively refined 15 time scale. Signatures that govern the evaluation of model complexity are the interannual variability, mean monthly variation in runoff (called regime curve), and the flow duration curve (FDC). Farmer et al. (2003) evaluated the climate, soil and vegetation controls on the variability of water balance through four signatures: gradient of the annual yield frequency graph, average yield over many years for each month, FDC, and magnitude and shape of the hydrograph. Shamir et al. (2005a) described a parameter estimation method based on hydrograph descriptors (total flow, range between the extreme values, monthly rising limb density of the hydrograph, monthly maximum flow and negative/positive change) that characterize dominant streamflow patterns at three timescales (monthly, yearly, and record extent). Detenbeck et al. (2005) calculated several hydrologic indices including daily flow indices (mean, median, coefficient of variation, and skewness), overall flood indices (flood frequency, magnitude, duration, and flood timing of various levels), low flow variables (mean annual daily minimum), and ranges of flow percentiles to study the relationship of the streamflow regime to watershed characteristics. Shamir et al. (2005b) presented two streamflow indices to
HESSD

11, 13385-13441, 2014
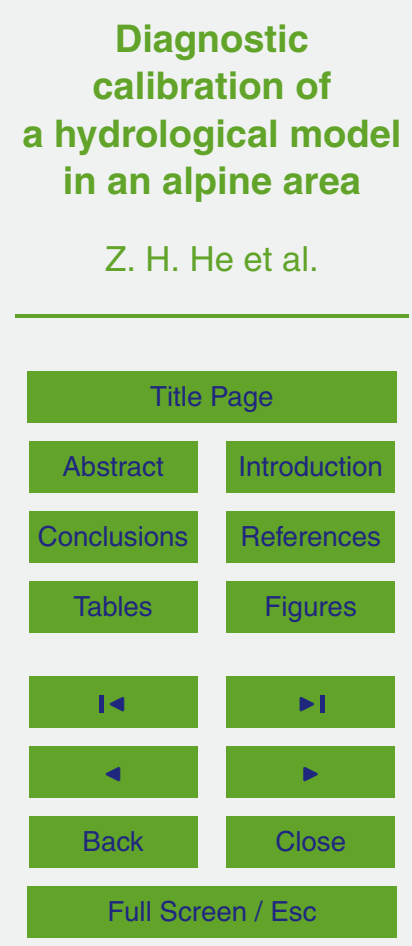

Printer-friendly Version

Interactive Discussion 
describe the shape of the hydrograph (rising/declining limb density, i.e. RLD and DLD) for parameter estimation in 19 basins of United States. Yadav et al. (2007) used similarity indices and hydrological signatures (runoff ratio and slope of the FDC) to classify catchments. Westerberg et al. (2011) selected several evaluation points on the FDC 5 to calibrate models, and compared two selection methods to evaluate their effects on parameter calibration.

Generally, the reported signatures have the following two characteristics: (1) they concentrate on the extraction of hydrologically meaningful information contained in hydrographs, and (2) they focus on either an entire study period or a special continuous 10 section of the entire period. They have occasionally considered temporal variability of runoff components and dominance of different runoff generation mechanisms during different periods (e.g. the seasonal switching of runoff generation mechanisms discussed in Tian et al., 2012). However, a hydrograph could be dominated by various components or water sources at different response times (Haberlandt et al., 2001; Eder et al., 2005). Within this in mind, a few studies have explored the use of hydrological information in time dimension for stepwise calibration. For example, Schaefli et al. (2005) presented a stepwise calibration method for 7 parameters in a high mountainous area: snow and ice melt degree-day factors were conditioned by mass balance, slow reservoir parameters were determined by base flow, reservoir coefficients were calibrated by summer runoff, and the direct runoff coefficient was used to control discharge during precipitation events. Another notable example is Hingray et al. (2010), in which the authors estimated the value of snowmelt degree-day factor in a mountain basin by progressively minimizing the differences between observed and simulated values of different magnitude hydrographs. There are also many other follow up studies.

In alpine areas, streamflow is composed of both snow/glacier meltwater and rainwater. The energy-based and temperature-index models are two principal approaches to simulate snow and glacier melt (Rango and Martinec, 1979; Howard, 1996; Kane et al., 1997; Singh et al., 2000; Fierz et al., 2003). To describe significant heterogeneity of temperature, precipitation, snow, and glacier, distributed hydrological models are

\section{HESSD}

$11,13385-13441,2014$

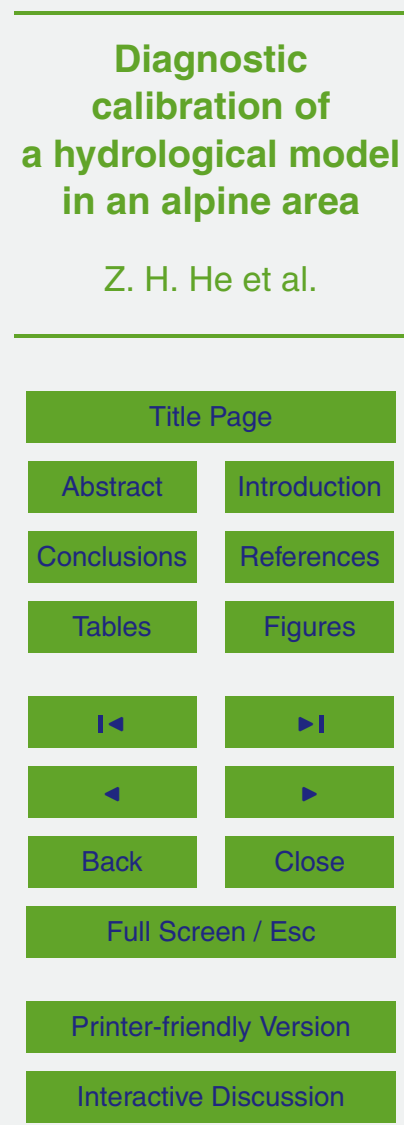

13389 
generally used for precipitation-runoff modeling in alpine regions (Daly et al., 2000; Klok et al., 2001 etc.). Also, the utilization of remotely sensing products of precipitation and snow cover data in the alpine runoff modeling has become more popular in recent years (Swamy and Brivio, 1997; Akyurek et al., 2011; Liu et al., 2012 etc.). Most of 5 these studies report sound simulation results. However, the need to develop an appropriate calibration strategy for precipitation-runoff modeling in alpine areas remains a key issue for two reasons: first, the hydrological processes are usually more complex (with snow/glacier melt and possibly soil freezing/thawing) than those in warmer areas, which implies a larger dimension of parameter $\left(R^{\mathrm{P}}\right)$ in the corresponding hydrological 10 model; second, measured data set useful for model identification is usually limited due to a sparse gauge network, which produces a small measurement dimension $\left(R^{\mathrm{M}}\right)$ far lower than $R^{\mathrm{P}}$. To address this problem, related studies are putting effort into two directions. One is to reduce the calibrated $R^{P}$ by estimating some of the parameters based on basin characteristics a priori. For example, Gurtz et al. (1999) proposed a paramGomez-Landesa and Rango (2002) obtained model parameters of ungauged basins from gauged basins by basin size, proximity of location, and shape similarities. Eder et al. (2005) estimated most of the parameters a priori from basin physiography before an automatic calibration was applied. The parameterization method may involve some uncertainties but be useful for the determination of insensitive parameters.

The second direction is to expand $R^{\mathrm{M}}$ by exploiting information from available data. For instance, Dunn and Colohan (1999) used baseflow data as additional criteria for model evaluation. Mendoza et al. (2003) exploited recession-flow data to estimate hydraulic parameters. Stahl et al. (2008) used glacier mass balance information combined

volume change data for optimizing melt and radiation factors, and glacier equilibrium line altitude for precipitation correction factors. Schaefli and Huss (2011) integrated the seasonal information of point glacier mass balance for model calibration by modifying the GSM-SOCONT model. Jost et al. (2012) introduced glacier volume loss calculated

HESSD

11, 13385-13441, 2014
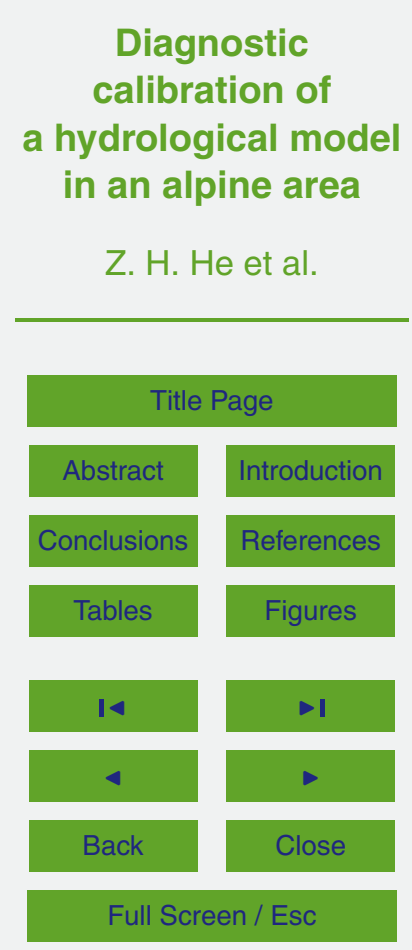

Printer-friendly Version

Interactive Discussion

\section{0}


by high-resolution digital elevation models to calibrate hydrologic model. Knowledge acquired from the aforementioned research indicates that the use of additional information (e.g. baseflow, recession flow, and glacier mass balance) can effectively help reduce parameter uncertainty by significantly expanding $R^{\mathrm{M}}$.

Hydrograph partitioning is another possible way to expand $R^{\mathrm{M}}$. Information about dominant hydrological processes contained in a hydrograph can be extracted by hydrograph partitioning or separation; this has long been a topic of interest in hydrology. Several different kinds of methods have been proposed (Pinder and Jones, 1969; McCuen, 1989; Nathan, 1990; Arnold et al., 1995, 1999; Vivoni et al., 2007), which can generally be classified into graphical methods, analytical methods, empirical methods, geochemical methods and automated program techniques (Nejadhashemi et al., 2009). Most of them primarily focus on the partitioning of baseflow and are not capable of identifying more than two components. With the advent of isotope methods, multi-component hydrograph separation models have been developed. However, these 15 models need be run for an extended period of time (usually a minimum of one hydrologic year) for the assumption that the isotopes of components are conserved to hold (Hooper and Shoemaker, 1986) and call for volumes of field data that are seldom available in poorly gauged and difficult to access alpine basins.

\subsection{Objectives and scope}

This paper explores the benefits of partitioning the hydrograph into several parts, each related to one combination of dominant water sources for runoff generation. The parameter group controlling each type of runoff generation is then calibrated using the corresponding partitioning hydrographic curves via a stepwise approach, and model deficiencies are diagnosed by evaluating the model simulations associated with each partitioning curve (as a diagnostic signature). We demonstrate the potential of this approach in an alpine area where streamflow is the result of complex runoff generation processes arising from combinations of storm events and snow/glacier melt. The influence of each type of water source (groundwater, snow meltwater, glacier meltwater, or 13391
HESSD

11, 13385-13441, 2014

\section{Diagnostic \\ calibration of \\ a hydrological model \\ in an alpine area \\ Z. H. He et al.}

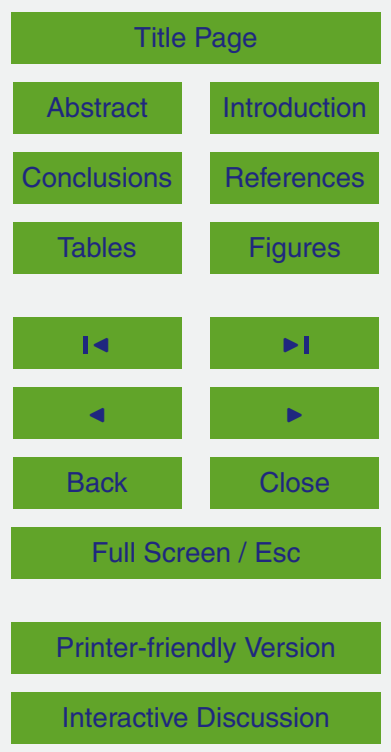

Interactive Discussion 
rainwater) varies in time and can be determined by an analysis of the dynamic spatiotemporal information in the available data series.

The paper is organized as follows. Section 2 contains a description of the geographic and hydrological characteristics of the study basin, including the main data sources 5 and data preprocessing. Section 3 details the proposed method of hydrograph partitioning and parameter calibration based on a semi-distributed model coupled with the temperature-index method. Section 4 presents the results and discusses the possible sources of uncertainty. Section 5 provides a summary of this study and discusses further applications of the partitioning strategy.

\section{Study area and data}

\subsection{Overview of the study area}

The study alpine area (Tailan River basin, TRB) is on the south slope of the Tianshan Mountain (one of the highest mountain areas in China) in the Xinjiang Uygur Autonomous Region of China and extends from $41^{\circ} 35^{\prime}$ to $42^{\circ} 05^{\prime} \mathrm{N}$ and $80^{\circ} 4^{\prime}$ to $80^{\circ} 35^{\prime} \mathrm{E}$, 15 covering a drainage area of $1324 \mathrm{~km}^{2}$. Elevation ranges from 1600 to 7100 ma.s.l. with an average value as high as 4100 ma.s.l. Precipitation occurs mainly in summer and rarely in winter, and winter precipitation always comes in the form of snowfall. Snow coverage accumulates in winter and ablates from spring into late summer when it melts away completely; the snow coverage dynamics can be obtained from MODIS data (see Fig. 4). The basin is highly glacierized with approximately $33 \%$ of the basin area covered by glacier ice (see Fig. 1). The glacier coverage stretches from approximately 3000 to 7100 ma.s.l. and exists mainly at an altitude range of 4000 to 5000 ma.s.l. Glacier melt and snowmelt form runoff as long as the temperature rises above a certain threshold and provide primary sources for downstream discharge.

TRB is a heavily studied alpine watershed in northwestern China. The relevant literature (Kang and Zhu, 1980; Shen et al., 2003; Xie et al., 2004; Gao et al., 2011; Sun
HESSD

$11,13385-13441,2014$

Diagnostic

calibration of

a hydrological model

in an alpine area

Z. H. He et al.

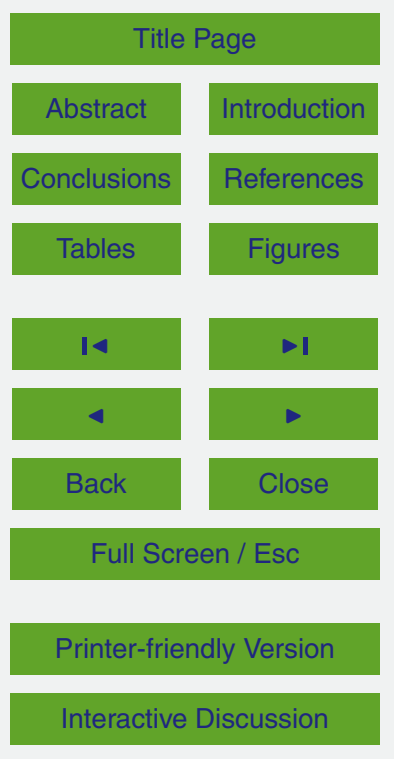


et al., 2012) are reviewed below, and the main conclusions about the hydrometeorological characteristics are summarized as follows:

1. The climate presents strong altitudinal variability. The mean annual precipitation in higher mountain areas is approximately $1200 \mathrm{~mm}$ (Kang et al., 1980), while it is approximately only $180 \mathrm{~mm}$ in the outlet plain area (Xie et al., 2004). The mean annual temperature ranges from below $0^{\circ} \mathrm{C}$ in mountain areas to approximately $9^{\circ} \mathrm{C}$ at the basin outlet (Sun et al., 2012).

2. Meltwater is the principal source of streamflow. Snow and glacier meltwater account for approximately $63 \%$ of the annual runoff (Kang et al., 1980). The contribution of rainwater is relatively lower and occurs mainly in the storm rain period (May to September) (Xie et al., 2004). Groundwater baseflow is smaller but dominates the streamflow in the winter (January, February and December), during which either rainfall or melt rarely occur (Kang et al., 1980).

3. The TRB river network is a simple fan system. Given large topographic drop and moderate drainage area, the runoff concentration time is no longer than one day (Xie et al., 2004). Melting and falling water can quickly flow into the main channel and reach the basin outlet.

\subsection{Data and preprocessing}

The Tailan gauging station (THS, 1602 ma.s.I.) is located the outlet of the watershed, where runoff, precipitation and temperature have been measured since 1957. To collect temperature and precipitation data at higher elevation, two automatic weather stations (AWS, product type TRM-ZS2) were set up in June 2011 (i.e. XT AWS, at 2116 ma.s.I. and TG AWS, at 2381 ma.s.I.). This relatively short record (from 1 July 2011-31 December 2012) was used to estimate the lapse rate of precipitation and temperature
HESSD

$11,13385-13441,2014$

\section{Diagnostic \\ calibration of \\ a hydrological model \\ in an alpine area \\ Z. H. He et al.}

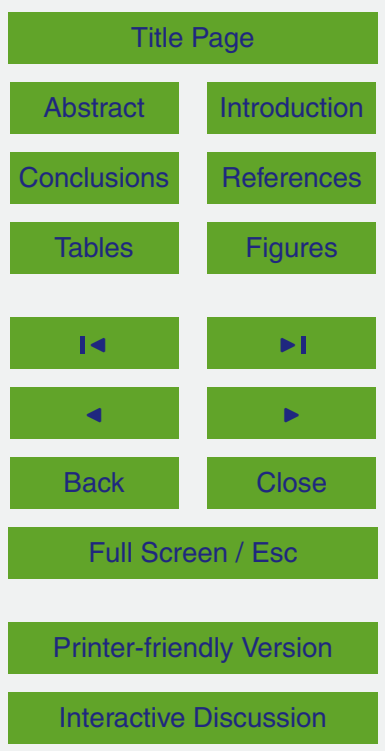
in an adjacent catchment (Kumalak basin) was used to validate the estimated temper- 
ature lapse rates. A digital elevation model (DEM) with a spatial resolution of $30 \mathrm{~m}$ was provided by the International Scientific \& Technical Data Mirror Site, Computer Network Information Center of the Chinese Academy of Sciences (http://www.gscloud.cn). Remotely sensed snow cover area (SCA) data were downloaded from the MODIS web5 site; the MOD10A2 and MYD10A2 products were used, both of which have a spatial resolution of $500 \mathrm{~m}$ and a temporal resolution of eight-days. Daily snow cover data was obtained by linear interpolation of the eight-day data. The China Glacier Inventory (CGI) (Shi, 2008) was used to derive glacier coverage in the TRB. In our experience, most of the snow melts away after the warm summer period and the lowest snow/ice coverage 10 in the year should, therefore, be roughly equal to the glacier coverage. Based on an analysis of filtered MODIS SCA (see Sect. 2.2.3), the lowest values of snow/ice coverage in the study period (2003-2012) are almost the same, which indicates that TRB glacier coverage is relatively stable during the study period. The DEM, river system, gauging stations and glacier distribution are shown in Fig. 1.

\subsubsection{Temperature lapse rate}

Altitudinal distribution of temperature can be estimated through the lapse rate (Rango and Martinec, 1979; Tabony, 1985). According to Aizen et al. (2000), rates of temperature decrease with increasing elevation are quite different in various months, and ignoring this difference may lead to significant errors in the simulation of snow accumulation and melt. The lapse rate was therefore estimated for each month. Temperature variations with altitude can be estimated by the following equation, i.e.:

$T=T_{\mathrm{o}}+T_{\mathrm{p}} \cdot(H-h)$

where, $T_{\mathrm{o}}$ is the temperature value at low altitude (THS in this study), and $T_{\mathrm{p}}$ is the temperature lapse rate (usually negative), $H$ and $h$ are the elevation values at high and low
HESSD

$11,13385-13441,2014$

Diagnostic

calibration of

a hydrological model

in an alpine area

Z. H. He et al.

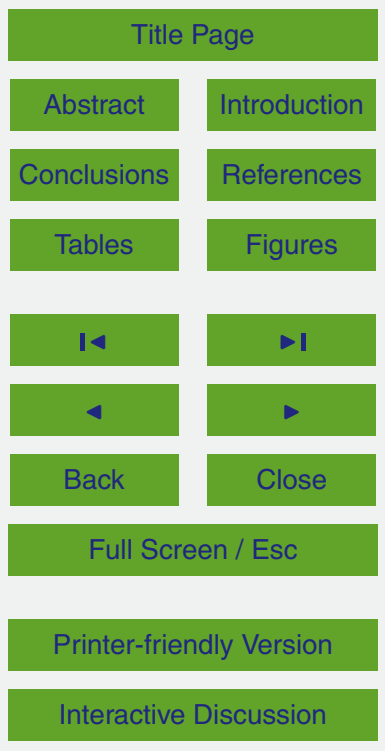


The values of $T_{\mathrm{p}}$ in different months are obtained by minimizing the error function, i.e.:

$\min : z=\sum\left(T_{i}-\left(T_{\mathrm{o} i}+T_{\mathrm{p}} \cdot(H-h)\right)\right)^{2}$

where, $i$ indicates the $i$ th day in the analyzed month, $T_{i}$ is the observed temperature in AWS, which is the mean value of the TG AWS and XT AWS in this study.

The temperature series data from 1 July 2011 to 31 December 2012 at THS, TG AWS and XT AWS were used to estimate the temperature lapse rate. The results (Ta-

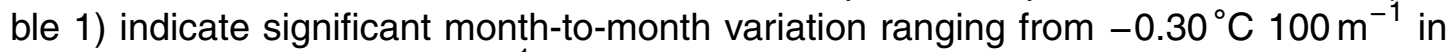
December to $-0.86^{\circ} \mathrm{C} 100 \mathrm{~m}^{-1}$ in August. To validate the temperature lapse rates, the estimated and observed temperature data at BT AWS were compared (Fig. 2). We also compared the estimated temperature by an annual constant lapse rate $\left(-0.62^{\circ} \mathrm{C}\right.$ $100 \mathrm{~m}^{-1}$, a similar value to previous studies, e.g. Tabony, 1985, and Tahir et al., 2011). This constant value is optimized by the same method in Eq. (2) but using all daily temperature measurements. Figure 2 indicates that the monthly lapse rate method performs better than the annual constant rate method at the BT station for all months 15 throughout the year. Further, the temperature curves estimated by monthly lapse rates for April to August match the observed ones rather well. Note that the estimated temperatures tend to underestimate observed ones for the rest of the months, which, however, will not affect the melt runoff significantly due to the general freezing condition during this period.

\subsubsection{Precipitation lapse rate}

Based on the precipitation series measured at THS, the monthly precipitation to annual precipitation ratio (Fig. 3) for the study period (2003-2012) indicates that precipitation occurs mainly in May to September. The lapse rate of precipitation was also estimated monthly, and a similar procedure as temperature was applied. The different is that the precipitation analysis was conducted at a weekly rather than daily time step, and the maximum measured precipitation of the two installed AWS was used instead of the

\section{Diagnostic \\ calibration of \\ a hydrological model \\ in an alpine area \\ Z. H. He et al.}

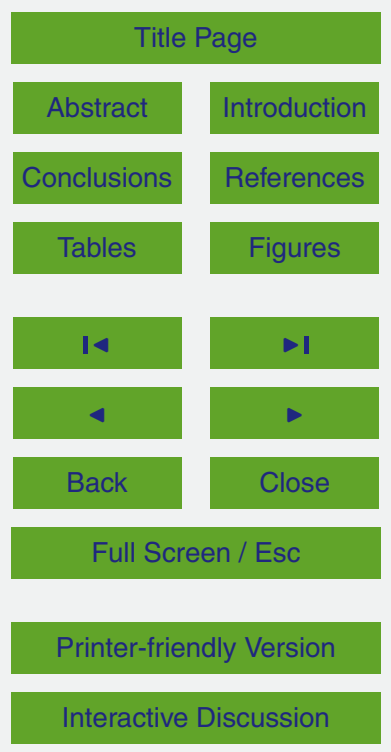

13395 
mean value. The analyzed period is limited to the storm rain period (May to September). Other months are not included due to the relatively small precipitation amount. The weekly precipitation lapse rates are listed in Table 2. Daily precipitation differences between higher and lower altitudes can be estimated as the weekly precipitation 5 lapse multiplied by the ratio of daily precipitation to the corresponding weekly amount in THS. The precipitation lapse rate was not validated against BT AWS because of significant differences in precipitation distribution between the two basins (i.e. Tailan and Kumalak).

\subsubsection{Filtering of MODIS snow cover area data}

Snow cover extent was obtained from MODIS products. The MOD10A2 and MYD10A2 products were downloaded from the website http://reverb.echo.nasa.gov. In total, we obtained 460 eight-day images (two tiles, h23v04 and h24v04) from 2003 to 2012 for each product. Given that the accuracy of the MODIS SCA product is affected by cloud coverage to a significant degree, the remotely sensed images should be filtered to avoid the noise from clouds before using it for hydrological modeling (Ackerman et al., 1998). The following three successive steps are adopted to filter the products based on previous reports (Gafurov and Bardossy, 2009; Wang et al., 2009; López-Burgos et al., 2013):

1. Satellite combination: the snow cover products of two satellites, Terra (MOD10A2) and Aqua (MYD10A2) were combined. As long as the value of a pixel is marked as snow in either satellite, the pixel value is marked as snow.

2. Spatial combination: inspecting the values of the nearest four pixels around one center pixel marked as cloud, if at least three of the four surrounding pixels are marked as snow, the center pixel is modified as snow.
HESSD

11, 13385-13441, 2014

Diagnostic

calibration of

a hydrological model

in an alpine area

Z. H. He et al.

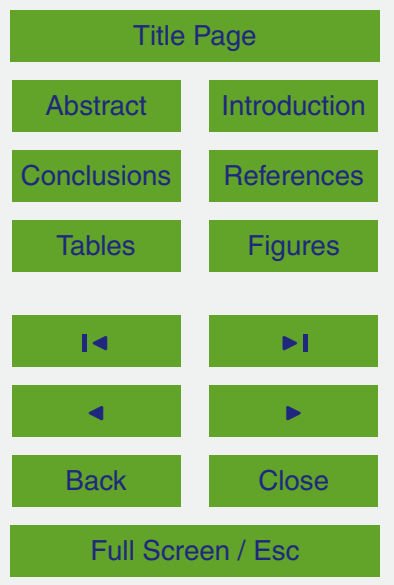

Printer-friendly Version

Interactive Discussion 
3. Temporal combination: if one pixel is marked as cloud, its values in the previous and following observations are investigated. If both of the two observed values are snow, then the present value of the same pixel is snow.

As an example, the filtered results from year 2004-2005 shown in Fig. 4 demonstrate 5 a significant reduction in fluctuation of the SCA products. We find that the lowest values of snow/ice coverage in all years (2003-2012) are relatively stable (from 2003 to 2012 are: $35,34,39,36,37,34,41,35,38,39 \%$, showing no obvious trend), which is close to the glacier coverage area (33\%) derived from the CGI data mentioned in Sect. 2.2. As mentioned before, MODIS snow/ice covered area in later summer is mainly 10 composed of glacier coverage when snow has been melt away completely. The filtered results indicate a relatively stable coverage of glacier in TRB.

\subsubsection{Altitudinal cumulative melt curve}

The daily temperature of each cell in MODIS SCA images can be estimated by a temperature lapse rate based on its elevation and daily temperature measured at THS. As long as the temperature exceeds a specific threshold value for melt (assumed to be $0^{\circ} \mathrm{C}$ in this study), a given cell was labeled as an active cell in terms of melt. The land cover type for each cell was classified into glacier, snow, and other land cover according to the CGI and MODIS SCA product. To obtain the area covered by snow only, we subtracted the glacier area in CGI from the SCA (a similar procedure can be found in Luo et al., 2013). When a glacier or snow cover cell is active, it is labeled as a melt cell, and the melt area is computed as the number of active cells multiplied by the area of a cell.

Organizing the melt area by elevation from low to high and summing the melt area at each elevation, we can get the altitudinal cumulative melt curve, which can be used to describe the spatiotemporal distribution of melt area. The altitudinal cumulative melt curves calculated from 2003 to 2012 for all months (Fig. 5) show that melt mainly occur from May to September, which coincides with the precipitation period. Snowmelt starts

\section{HESSD}

11, 13385-13441, 2014
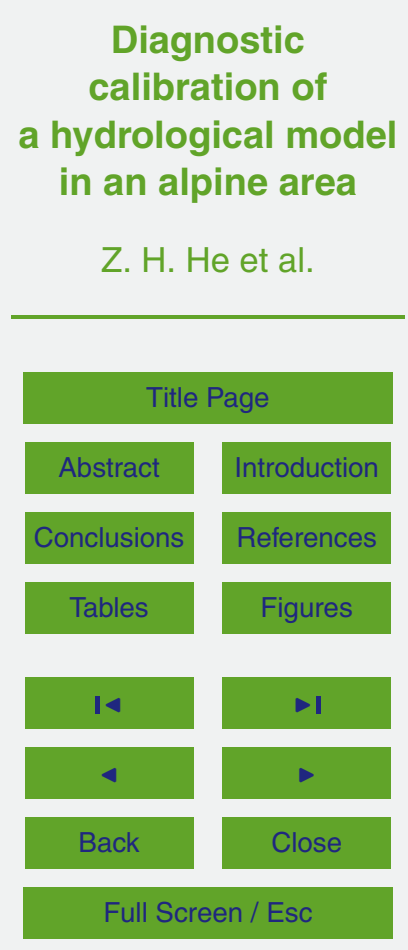

Printer-friendly Version

Interactive Discussion 
at an elevation of approximately 1650 ma.s.l., while glacier melt starts at an elevation of approximately 2950 ma.s.I., which has an important implication for hydrograph partitioning.

\section{Methodology}

5 Theoretically, every drop of water in the streamflow comes ultimately from precipitation. Practically, we can consider water sources for runoff generation in alpine areas as mainly consisting of meltwater from snow and glacier, rainwater, and groundwater. Groundwater at the basin scale is recharged by direct infiltration and run-on infiltration of meltwater or rainwater, and it is mainly discharged as baseflow via a subsurface flow path (especially in alpine areas where the large elevation gradient favors baseflow discharge). For the purpose of hydrograph partitioning, we can consider recharge to be a separate water source for streamflow, independent of meltwater and rainwater, which principally forms the baseflow part of a hydrograph. The remaining part of a hydrograph is principally formed by meltwater and rainwater via surface flow path (Blöschl et al., 2013). We develop three indices to indicate the water sources for runoff generation at the daily time scale. The hydrograph is further partitioned into several sub-parts based on the indices values. Each sub-part is dominated by one or more water sources for runoff generation. With the partitioning hydrographic curves, the parameters of hydrological models are correspondingly grouped by runoff generation mechanisms and cal-

ibrated in a stepwise fashion. We use the THREW model coupled with a temperatureindex module as an exploratory tool. To better demonstrate usefulness of the proposed methods, only the runoff generation related parameters, which are also significantly sensitive parameters (see Sect. 4.6), are calibrated. Other insensitive parameters are fixed at their initial values, specified a priori from the literature or by expert knowledge.

\section{HESSD}

11, 13385-13441, 2014

\section{Diagnostic \\ calibration of \\ a hydrological model \\ in an alpine area \\ Z. H. He et al.}

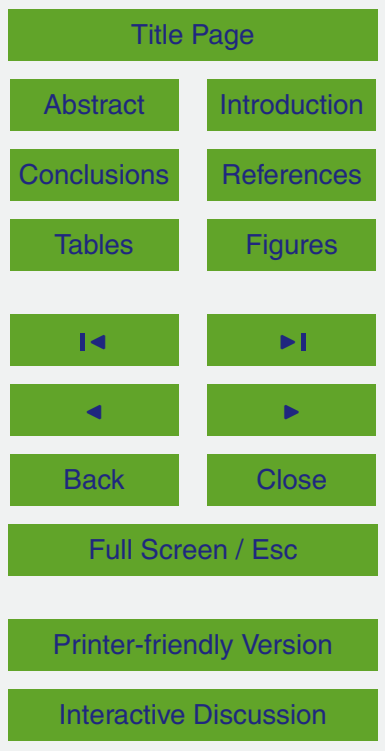




\subsection{An index-based method for hydrograph partitioning}

In alpine areas, the relative contribution of different runoff water sources to the total streamflow varies throughout the year (Martinec et al., 1982; Dunn and Colohan, 1999; Yang et al., 2007). For the rainwater source, Fig. 3 shows that precipitation in TRB 5 presents strong seasonality and primarily concentrates (more than $76 \%$ ) in the storm rain period from May to September. During the relatively dry period from October to April, mean precipitation gauged at the THS is just $43 \mathrm{~mm}$, while precipitation in the higher mountainous region is mainly snowfall. Therefore, surface runoff induced by rainwater can rarely occur during relative dry period. It is reasonable to assume that the rainwater source can only contribute to the surface runoff part of a hydrograph on the same day during the storm rain period (May to September) except for the baseflow occurring much later.

For the meltwater sources, the altitudinal cumulative melt curves (Fig. 5) show that the areas experiencing glacier melt and snowmelt change significantly with elevation.

15 Melt of glacier and snow begins at different elevations in different months, i.e. glacier melt can only occur in the areas higher than $2950 \mathrm{~m}$ (the lower elevation limit of glacier coverage) while snowmelt can occur in areas higher than $1650 \mathrm{~m}$. It can be deduced that snowmelt generally occurs at lower elevations than glacier melt. Remember that temperature decreases with increase in altitude. There should exist a period of time during which temperature at $1650 \mathrm{~m}$ is higher than snowmelt threshold while temperature above $2950 \mathrm{~m}$ is lower than glacier threshold and thus snowmelt does occur but glacier melt not.

The groundwater source should be a dominant source for the baseflow part of a hydrograph and, of course, it dominates the recession limb of a hydrograph (part of a baseflow partition) when no rainfall or melting occurs.

Based on the above physical understanding, we can partition the hydrograph using the following three indices:

\section{HESSD}

$11,13385-13441,2014$
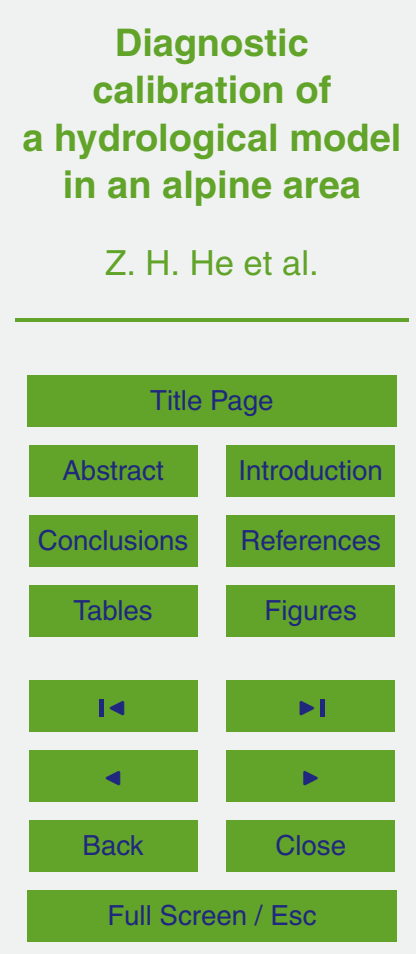

Printer-friendly Version

Interactive Discussion 
1. Date index $\left(D_{i}\right): D_{i}$ is used to distinguish the dates on which rainfall and thus possible rainwater directly runoff process occurs. For simplicity, in this study we use $D_{i}$ to distinguish dry period and storm rain period and assume no rainfall in the dry period, i.e.

2. Snowmelt index $\left(S_{i}\right): S_{i}$ indicates whether snowmelt possibly occurs on a given day:

$S_{i}= \begin{cases}1, & \text { for days when temperature at altitude } 1650 \mathrm{~m} \text { is higher than } 0{ }^{\circ} \mathrm{C} \\ 0, & \text { for other days }\end{cases}$

3. Glacier melt index $\left(G_{i}\right): G_{i}$ is used to identify days when glacier melt possibly occurs:

$G_{i}= \begin{cases}1, & \text { for days when temperature at altitude } 2950 \mathrm{~m} \text { is higher than } 0{ }^{\circ} \mathrm{C} \\ 0, & \text { for other days }\end{cases}$

The hydrograph is then partitioned according to the three indices by using the following rules:

$Q= \begin{cases}Q_{\mathrm{SB}} & \text { for } S_{i}+G_{i}+D_{i}=0 \\ Q_{\mathrm{SB}}+Q_{\mathrm{SM}} & \text { for } S_{i}-G_{i}-D_{i}=1 \\ Q_{\mathrm{SB}}+Q_{\mathrm{SM}}+Q_{\mathrm{GM}} & \text { for } G_{i}-D_{i}=1 \\ Q_{\mathrm{SB}}+Q_{\mathrm{SM}}+Q_{\mathrm{GM}}+Q_{\mathrm{R}} & \text { else for } D_{i}=1\end{cases}$

15 where, $Q$ is the overall streamflow series, $Q_{\mathrm{SB}}$ stands for the baseflow generated by groundwater source, $Q_{\mathrm{SM}}$ for snow meltwater runoff, $Q_{\mathrm{GM}}$ for glacier meltwater runoff, and $Q_{\mathrm{R}}$ for rainwater directly runoff. The partitioning principles are described as follows:

Diagnostic

calibration of

a hydrological model

in an alpine area

Z. H. He et al.

Title Page

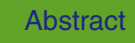

Introduction

Conclusions

Tables

References

Figures

14

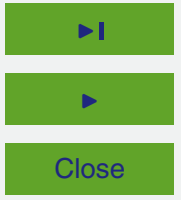

Back

Close 
1. Groundwater is the dominant component $\left(Q=Q_{\mathrm{SB}}\right)$ when both melt and rainwater directly runoff do not occur. This condition is mathematically equivalent to $S_{i}+G_{i}+$ $D_{i}=0$, which requires $S_{i}=0, G_{i}=0$, and $D_{i}=0$;

2. Snow meltwater and groundwater are the dominant components $\left(Q=Q_{\mathrm{SB}}+Q_{\mathrm{SM}}\right)$ when the temperature is higher than $0{ }^{\circ} \mathrm{C}$ at 1650 ma.s.l. and lower than $0^{\circ} \mathrm{C}$ at 2950 ma.s.I. (equivalent to $S_{i}-G_{i}-D_{i}=1$, which requires $S_{i}=1, G_{i}=0$, and $\left.D_{i}=0\right)$;

3. Snow meltwater and glacier meltwater coupled with groundwater dominate $(Q=$ $\left.Q_{\mathrm{SB}}+Q_{\mathrm{SM}}+Q_{\mathrm{GM}}\right)$ on days when the temperature at 2950 ma.s.l. exceeds $0{ }^{\circ} \mathrm{C}$ in October to April. This is equivalent to $G_{i}-D_{i}=1$, which means $G_{i}=1, D_{i}=0$, and $S_{i}=1$, noting that $S_{i}$ must be equal to 1 when $G_{i}=1$ for the decreasing nature of temperature along altitude;

4. Finally, all sources are mixed $\left(Q=Q_{\mathrm{SB}}+Q_{\mathrm{SM}}+Q_{\mathrm{GM}}+Q_{\mathrm{R}}\right)$ for other days in the storm rain period (May to September, $D_{i}=1$ ). Each category contains days that could be continuous or discontinuous in time and could lie within different weeks due to temporal variability of precipitation and temperature.

\subsection{Tsinghua Representative Elementary Watershed Hydrological model}

The Tsinghua Representative Elementary Watershed model (THREW model) used for the hydrological simulation in this study, has been successfully applied in many watersheds in both China and the United States (see Tian et al., 2008, 2012; Li et al., 2012; Liu et al., 2012 etc.), including an application to a high mountainous catchment of Urumqi River basin by Mou et al. (2008). The THREW model adopts the REW (Representative Elementary Watershed) approach to conceptualize a watershed, where REW is the sub-catchment unit for hydrological modeling. The study basin was divided into

several units (REW) based on a digital elevation model. Sub-catchment units were further divided into a surface and sub-surface layer, each layer containing several sub-

\section{HESSD}

$11,13385-13441,2014$

\section{Diagnostic \\ calibration of \\ a hydrological model \\ in an alpine area \\ Z. H. He et al.}

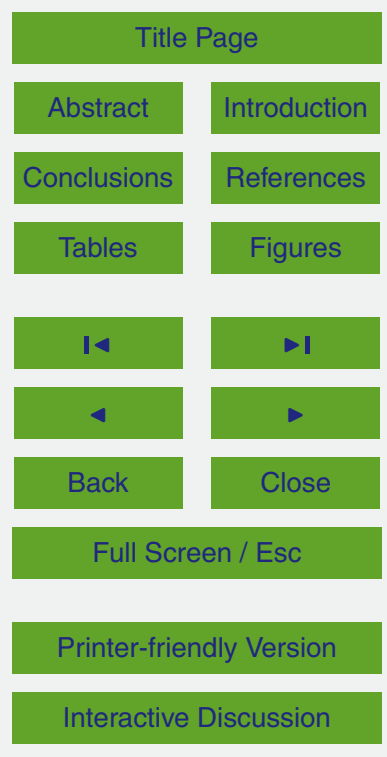


zones. The sub-surface layer is composed of two zones: saturated zone and unsaturated zone, and the surface layer consists of six zones: vegetated zone, bare soil zone, snow covered zone, glacier covered zone, sub-stream-network zone, and main channel reach; see Tian et al. (2006) for further details.

The main runoff generation processes simulated by the THREW model include rainfall surface runoff, groundwater baseflow, snowmelt and glacier melt. Rainfall surface runoff is simulated by a Xin'anjiang module, which adopts a water storage capacity curve to describe non-uniform distribution of water storage capacity of a sub-catchment (Zhao, 1992). The storage capacity curve is determined by two parameters (spatial av10 eraged storage capacity WM and shape coefficient $B$ ). Rainfall surface runoff forms on areas where storage is replete. Replete areas are calculated by the antecedent storage and current rainfall. The saturation excess runoff is computed based on water balance. The remainder of rainfall can infiltrate into soil and become additional contributions to groundwater. Groundwater forms baseflow that is separately calculated by two coefficients (KKA and KKD). The Xin'anjiang module has been successfully applied to the Qiedeke, Kaidu, Manasi and Kahai basins in Tianshan Mountain by different authors (Jiang, 1987; Yang et al., 1987; Mu and Jiang, 2009), which indicates its applicability in our study area.

For the simulation of melt processes in this study, the THREW model was modified 20 to couple with the temperature-index method, given the easy accessibility of air temperature data and generally good model performance of the temperature-index model (Hock, 2003; Singh et al., 2000). Snow and glacier melt are simulated using separate degree-day factors (snowmelt degree day factor $D_{\mathrm{s}}$ and glacier melt degree day factor $D_{\mathrm{g}}$ ). Glacier melt only occurs in glacier area according to CGI, which remains stable during the study period (2003-2012, see discussion in Sect. 2.2.3). Precipitation in the snow and glacier zone is divided into rainfall and snowfall according to two threshold temperature values $\left(0\right.$ and $2.5^{\circ} \mathrm{C}$ are adopted in this study according to $\mathrm{Wu}$ and $\mathrm{Li}, 2007$ ), i.e. when temperature is higher than $2.5^{\circ} \mathrm{C}$, all precipitation is rainfall, when temperature is lower than $0{ }^{\circ} \mathrm{C}$, all precipitation is snowfall, and when tempera-
HESSD

$11,13385-13441,2014$
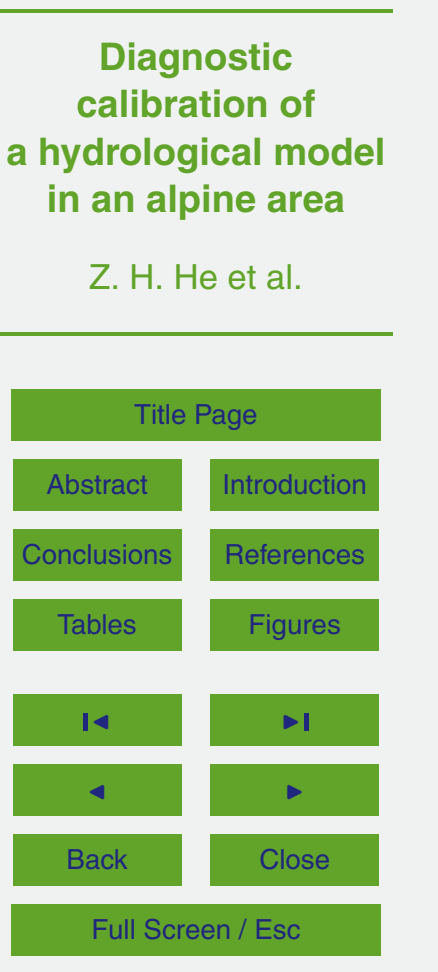

Printer-friendly Version

Interactive Discussion 
ture falls between the two thresholds, precipitation is divided into rainfall and snowfall half by half (a simple division scheme adopted here). Rainfall on glacier areas forms runoff and flows into the stream-network directly without infiltration into soil. Snow water equivalent (SWE) on glacier areas is updated by combining snowfall and snowmelt, 5 and for simplicity, snow is assumed to cover all glacier areas when the corresponding SWE is not zero. Snowmelt in glacier areas is simulated using snow degree-day factor $D_{\mathrm{s}}$ until it melts away completely. Snow cover area in non-glacier area is updated using MODIS data. Since MODIS SCA products (i.e. MYD10A2) are available from 2003, the model simulation period is from 2003 to 2012, of which 2003-2007 for calibration and 2008-2012 for evaluation. The time step for simulation is daily.

\subsection{Stepwise calibration of grouped parameters upon partitioning curves}

Model parameters are grouped a priori according to their connection with causal physical mechanisms (see Table 3). According to Xie et al. (2004) and Kang et al. (1980), parameters that control groundwater baseflow, snowmelt, glacier melt, and rainwater 5 surface runoff should be the most sensitive parameters for the runoff simulation (also see our sensitivity analysis in Sect. 4.6). These parameters are subjected to calibration in this study. They are related to the corresponding hydrograph parts and then calibrated in a stepwise manner: first, groundwater baseflow parameters (KKA and KKD) are estimated based on the $Q_{\mathrm{SB}}$ part of the hydrograph. Second, snowmelt degree 20 day factor $\left(D_{\mathrm{S}}\right)$ is calibrated upon the $Q_{\mathrm{SB}}+Q_{\mathrm{SM}}$ part. Third, glacier melt degree-day factor $\left(D_{\mathrm{g}}\right)$ is determined according to the $Q_{\mathrm{SB}}+Q_{\mathrm{SM}}+Q_{\mathrm{GM}}$ part. Finally, rainfall surface runoff parameters $(B, \mathrm{WM})$ are calibrated on days when $D_{i}$ equals to1, i.e. the $Q_{\mathrm{SB}}+Q_{\mathrm{SM}}+Q_{\mathrm{GM}}+Q_{\mathrm{R}}$ part of hydrograph.

In each step, only the specific parameter group is subjected to calibration. The pa25

rameters determined in the previous steps are kept constant, and all other parameters that will be calibrated in the next steps adopt their initial values. As the simulation in each step can, to some degree, be affected by the initial conditions produced in the preceding step, an iterative procedure is implemented to progressively minimize

\section{HESSD}

$11,13385-13441,2014$
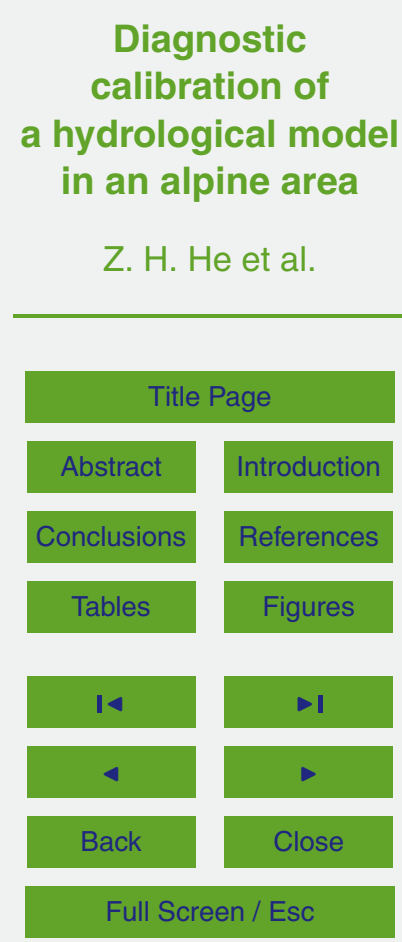

Printer-friendly Version

Interactive Discussion 
this influence. The parameter groups are first calibrated based on the corresponding hydrograph parts, and then the stepwise sequence is repeated until the calibrated parameters converge, i.e. the difference in parameter values between two contiguous iterations is less than $10 \%$. In each calibration step, we use RMSEIn (Eq. 7, emphasizing 5 low flow) or RMSE (Eq. 8, emphasizing high flow) as objective function for parameter optimization. The remaining, insensitive, parameters are determined a priori according to previous modeling experience (mainly from Sun et al., 2012) and listed in Table 3. The initial values of the calibrated parameters are also determined a priori according to Sun et al. (2012) and Tian et al. (2012).

10 The overall streamflow can be simulated with all calibrated parameters, which is evaluated with NSE and NSEIn (logarithm Nash Criterion) values. Given that it is relatively easier to obtain high evaluation merit values in snowmelt driven basins due to strong seasonality of streamflow, we further adopt a simple benchmark model (the inter-annual mean value for every calendar day) to evaluate performance of the proposed method by subtracting streamflow seasonality. This benchmark model is proposed by Schaefli and Gupta (2007) for basins having a relatively constant seasonality. The improvement of a model comparing to the benchmark model is quantified by the BE, see Eq. (9) for detail.

RMSEIn $=\sqrt{\frac{1}{n} \sum_{i=1}^{n}\left(\log Q_{\text {obs }}(i)-\log Q_{\text {sim }}(i)\right)^{2}}$

20 RMSE $=\sqrt{\frac{1}{n} \sum_{i=1}^{n}\left(Q_{\text {obs }}(i)-Q_{\text {sim }}(i)\right)^{2}}$
HESSD

$11,13385-13441,2014$
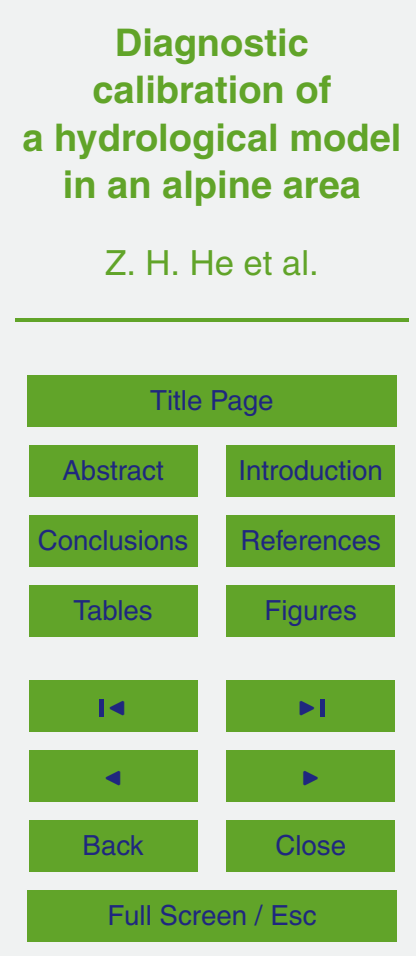

Printer-friendly Version

Interactive Discussion 
$\mathrm{BE}=1-\frac{\sum_{i=1}^{n}\left(Q_{\mathrm{obs}}(i)-Q_{\mathrm{sim}}(i)\right)^{2}}{\sum_{i=1}^{n}\left(Q_{\mathrm{obs}}(i)-Q_{\mathrm{ben}}(i)\right)^{2}}$

HESSD

$11,13385-13441,2014$

\section{Results and discussion}

\subsection{Partitioning hydrographic curves}

5 The hydrograph from 2003 to 2012 was partitioned based on Eq. (6). In total, we obtained four kinds of partitioning curves, i.e. $Q_{\mathrm{SB}}$ part, $Q_{\mathrm{SB}}+Q_{\mathrm{SM}}$ part, $Q_{\mathrm{SB}}+Q_{\mathrm{SM}}+Q_{\mathrm{GM}}$ part and $Q_{\mathrm{SB}}+Q_{\mathrm{SM}}+Q_{\mathrm{GM}}+Q_{\mathrm{R}}$ part. As an example, the partitioning curves in 2003 are shown in Fig. 6 , in which the melting period ranges from late February to late November (labeled as red and green dots). Snowmelt (red dots) starts in February and ends in November, while glacier melt (green dots) starts later (March) and stops earlier (October). This melt situation agrees well with the previous studies of Kang et al. (1980) and Sun et al. (2012). Hydrograph parts dominated by groundwater source mainly fall into December, January and February and are denoted by black dots. The rainwater surface runoff occurs in the storm rain period only (May to September, denoted by blue dots). The total number of days of $Q_{\mathrm{SB}}+Q_{\mathrm{SM}}$ part from 2003 to 2007 is 365, and that of $Q_{\mathrm{SB}}+Q_{\mathrm{SM}}+Q_{\mathrm{GM}}$ part is 249 , while the $Q_{\mathrm{SB}}+Q_{\mathrm{SM}}+Q_{\mathrm{GM}}+Q_{\mathrm{R}}$ part occupies 765 days. The numbers of non-melt days (i.e. the $Q_{\mathrm{SB}}$ part, due to glacier melt generally occurs in the $Q_{\mathrm{SB}}+Q_{\mathrm{SM}}+Q_{\mathrm{GM}}+Q_{\mathrm{R}}$ part) in the five years are 114, 80, 89, 96, and 68 , respectively. Correspondingly, the mean temperatures in those years gauged at the THS are $8.9,10.1,9.9,10.4$, and $11.3^{\circ} \mathrm{C}$, respectively. A lower mean annual temperature causes a longer non-melt period in that year and vice versa. Note that the partitioning curves can be discontinuous in time due to the spatial-temporal variability of temperature.

Diagnostic

calibration of

a hydrological model

in an alpine area

Z. H. He et al.

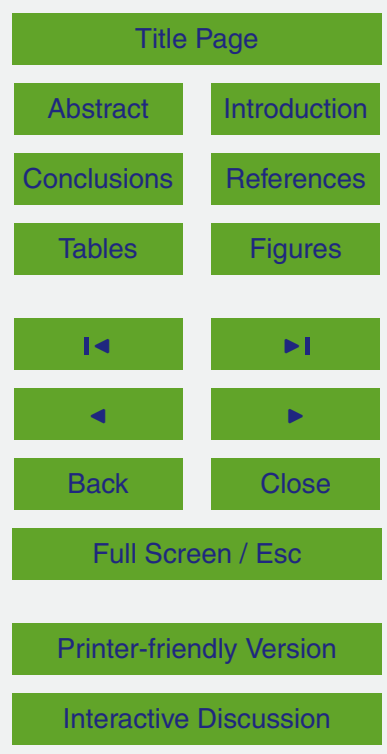

Interactive Discussion 


\subsection{Model calibration by the stepwise method}

The six key parameters (KKA, KKD, $D_{\mathrm{s}}, D_{\mathrm{g}}, \mathrm{WM}$, and $B$ ) were firstly calibrated by the proposed stepwise and iterative method. To focus on baseflow generated by the groundwater source during the $Q_{\mathrm{SB}}$ period, the RMSEIn metric that emphasizes low

5 flow is chosen as the evaluation criterion for the calibration of parameters KKA and $\mathrm{KKD}$. Conversely, high flow is our focus for the remaining periods $\left(Q_{\mathrm{SB}}+Q_{\mathrm{SM}}, Q_{\mathrm{SB}}+\right.$ $\left.Q_{\mathrm{SM}}+Q_{\mathrm{GM}}, Q_{\mathrm{SB}}+Q_{\mathrm{SM}}+Q_{\mathrm{GM}}+Q_{\mathrm{R}}\right)$ and the RMSE metric is chosen as the evaluation criterion for calibration of parameters $D_{\mathrm{s}}, D_{\mathrm{g}}$, and WM and $B$. To deal with interaction between steps, an iterative calibration approach was adopted. A total of five iterations was implemented until the parameter estimates became stable; the simulation of each kind of partitioning curve in each step of the last iteration is presented in Fig. 7. The calibrated parameters are shown in Table 4 and the evaluation merits are listed in Table 5.

Figure 7a shows that the magnitude of baseflow in $Q_{\mathrm{SB}}$ part was captured well at most of the times. The RMSEln merit is $0.302 \mathrm{~m}^{3} \mathrm{~s}^{-1}$, and the parameters KKA and KKD were determined as 1.1 and 0.002 respectively. Streamflow in the $Q_{\mathrm{SB}}+Q_{\mathrm{SM}}$ part is dominated by both snow meltwater and groundwater. The Fig. $7 \mathrm{~b}$ shows that melt peak flow events have also been captured well by a calibrated $D_{\mathrm{s}}$ as $2.5 \mathrm{~mm}^{\circ} \mathrm{C}^{-1}$ day $^{-1}$ after the determination of KKA and KKD in the first step. For the $Q_{\mathrm{SB}}+Q_{\mathrm{SM}}+Q_{\mathrm{GM}}$ part, glacier meltwater began to control the streamflow in combination with snow meltwater and groundwater. Snowmelt and baseflow were determined a priori by previously calibrated parameters. The remaining residual between the simulated and observed discharge can be attributed to glacier melt alone, which was thus used for the calibration of glacier melt factor $D_{\mathrm{g}}$. The RMSE value for this hydrograph parti25 tion was optimized as $4.784 \mathrm{~m}^{3} \mathrm{~s}^{-1}$ and we obtained a sound simulation by a calibrated $D_{\mathrm{g}}$ as $7.2 \mathrm{~mm}^{\circ} \mathrm{C}^{-1}$ day $^{-1}$ as shown in Fig. 7c. During the storm rain periods $\left(Q_{\mathrm{SB}}+Q_{\mathrm{SM}}+Q_{\mathrm{GM}}+Q_{\mathrm{R}}\right.$ part), rainwater directly runoff is an additional important component of river runoff. Similarly, parameters WM and $B$ can be calibrated separately after

Diagnostic

calibration of

a hydrological model

in an alpine area

Z. H. He et al.

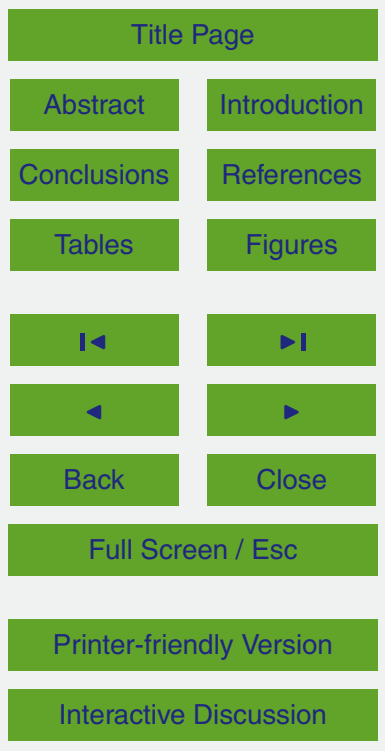


priori determination of melt runoff and groundwater baseflow. The simulated RMSE value in this period is $12.650 \mathrm{~m}^{3} \mathrm{~s}^{-1}$, with calibrated $\mathrm{WM}=10.50 \mathrm{~cm}$ and $B=0.80$. The overall daily streamflow simulation is obtained by combining the four partitions together (see Fig. 8a). The corresponding NSE index is 0.881 and NSEln is 0.929 . Generally 5 the results suggest a sound simulation compared to the observation.

To be noted, the calibrated values of melt degree day factors $D_{\mathrm{s}}\left(2.5 \mathrm{~mm}^{\circ} \mathrm{C}^{-1}\right.$ day $\left.^{-1}\right)$ and $D_{\mathrm{g}}\left(7.2 \mathrm{~mm}^{\circ} \mathrm{C}^{-1}\right.$ day $\left.^{-1}\right)$ are similar to the values obtained in other studies in Tainshan area, e.g. $D_{\mathrm{s}}$ is calibrated as $2.5 \mathrm{~mm}^{\circ} \mathrm{C}^{-1}$ day ${ }^{-1}$ by Liu et al. (2012), and $D_{\mathrm{s}}$ and $D_{\mathrm{g}}$ are estimated as 3.1 and $7.3 \mathrm{~mm}^{\circ} \mathrm{C}^{-1}$ day $^{-1}$ respectively based on observed mass 10 balance data by Liu et al. (1999), which indicates the robustness of our calibration method.

\subsection{Comparison to automatic calibration method}

For comparison, we also carry out an automatic calibration with the help of the $\varepsilon$ NSGAll algorithm, an optimization method developed by Deb et al. (2002) and Kol15 lat and Reed (2006). The six parameters were calibrated together and evaluated by NSE value of the overall hydrograph. The run time of the automatic algorithm is about 5 weeks ( $840 \mathrm{~h}$ on a desktop equipped with an Intel Core i7 CPU with $2.8 \mathrm{GHz}$ ). The NSE value for the final optimized parameters is 0.868 , and the NSEln value is 0.846 (Fig. 8b), both of which are lower than the values obtained by the proposed 20 stepwise method. The parameters calibrated by $\varepsilon$-NSGAll are listed in Table 4, and are different from those calibrated by the stepwise method. Specifically, the snowmelt degree-day factor $\left(D_{\mathrm{s}}\right)$ and groundwater baseflow parameters (KKA and KKD) obtained by $\varepsilon$-NSGAIl are $2.03 \mathrm{~mm}^{\circ} \mathrm{C}^{-1}$ day $^{-1}$ and 5.6 and 99.1 respectively. The evaluation merits of RMSE and RMSEln for each partitioning curve are also shown in Table 5. 25 In general, the simulation by the automatic algorithm is not as good as that by the stepwise method, especially for the low and middle flow partitions $\left(Q_{\mathrm{SB}}+Q_{\mathrm{SM}}\right.$ and

\section{HESSD}

$11,13385-13441,2014$
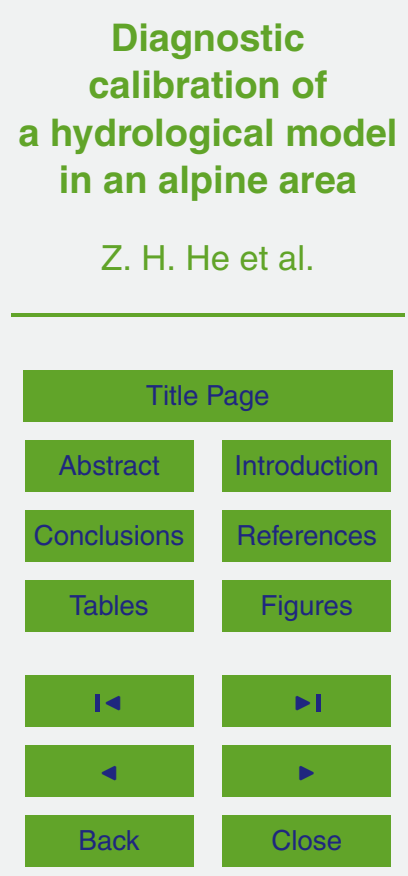

Full Screen / Esc

Printer-friendly Version

Interactive Discussion 
$\left.Q_{\mathrm{SB}}+Q_{\mathrm{SM}}+Q_{\mathrm{GM}}\right)$. This may be due to the tendency of NSE-based automatic calibration to emphasize high flows.

To make a further evaluation, a benchmark model suggested by Schaefli and Gupta (2007) is used for the comparison, which simply simulates daily runoff as the inter5 annual daily mean value. Simulation results by the benchmark model are shown in the Fig. 8c, which shows NSE value as 0.815 and NSEln value as 0.923 . The high NSE and NSEIn values can be attributed to the strong seasonality of stream discharge in the study basin (Schaefli and Gupta, 2007). The BE index (Eq. 9, see Table 5) is used to measure the improvement of simulations by the calibration methods compared 10 to the benchmark model. A positive value for BE means that the evaluated method outperforms the benchmark model. Figure 8 shows the simulations of daily streamflow by the three methods (Fig. $8 \mathrm{a}$ by stepwise calibration method, Fig. $8 \mathrm{~b}$ by automatic calibration method and Fig. $8 \mathrm{c}$ by benchmark model), which shows better simulation by the two calibration runs with THREW model than the benchmark model (BE values are both positive). The stepwise calibration run obtained a BE value of 0.355 , while BE of the automatic calibration run is 0.271 . The benchmark model describes the mean value of daily discharge on each calendar day. The higher the BE value is, the better the seasonal variability of the hydrograph is captured by the evaluation method. The higher $\mathrm{BE}$ value in the stepwise calibration method can be attributed to the better simulation of middle and low flows which are dominated by groundwater and melt water (Fig. 8a). However, BE values simulated by two calibrated parameter sets are both relatively low, which is attributed to the poor mimic of the (rapidly rising and falling) peaks.

Note that the automatic calibration method based on NSE value of the overall hydrograph adopts 1-D measurement information to optimize four parameter groups. Benefitting from the partitioning curves, however, the stepwise calibration method increases

the dimension of measurement information to four. The measurement dimension is now equal to the number of parameter groups, and the grouped parameters can be optimized according to their corresponding runoff components separately. A sound simulation of the overall hydrograph is obtained by the reasonable reproduction of the

\section{Diagnostic \\ calibration of \\ a hydrological model \\ in an alpine area \\ Z. H. He et al.}

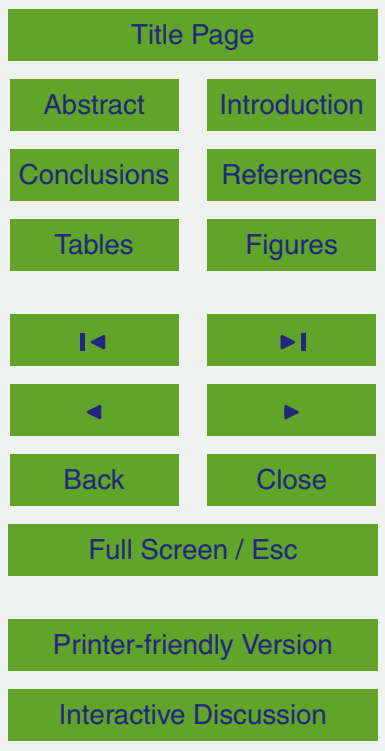

13408 
separate partitioning curves. Therefore, parameters calibrated by the stepwise method are inclined to have more explicit physical basis.

In regards to computation efficiency, the stepwise calibration required 385 runs of the model to complete, with each model run taking about $1.5 \mathrm{~min}$ and the total computation 5 time being about $10 \mathrm{~h}$. In contrast, the state-of-the-art automatic calibration algorithm required about 5 weeks of CPU time consumption on a desktop equipped with an Intel Core i7 CPU and $2.8 \mathrm{GHz}$. The comparison indicates that the stepwise calibration method is both more physically based as well as more computationally efficient.

\subsection{Evaluation for the stepwise calibration method}

10 The parameter set calibrated by the stepwise method is applied to the evaluation period (2008 2012), and the daily discharge simulation is shown in Fig. 9a. The evaluation merits are listed in Table 5. The NSE, NSEln and RMSE values for the whole period indicate sound evaluation results but general lower performance compared to calibration period. However, the evaluation results by the stepwise method are still significant bet15 ter than the benchmark model, which obtained a NSE value as low as 0.577 (Fig. 9b and Table 5). The BE value in evaluation period by the stepwise calibration method is 0.413. Furthermore, from the partition perspective, the RMSEln and RMSE values for four partitions in Table 5 show that the low flow simulations $\left(Q_{\mathrm{SB}}, Q_{\mathrm{SB}}+Q_{\mathrm{SM}}\right.$, and $Q_{\mathrm{SB}}+Q_{\mathrm{SM}}+Q_{\mathrm{GM}}$ parts) are pretty good and even outperform the calibration simula20 tions. The high flow simulation $\left(Q_{\mathrm{SB}}+Q_{\mathrm{SM}}+Q_{\mathrm{GM}}+Q_{\mathrm{R}}\right.$ part) is, however, insufficient, with RMSE $16.727 \mathrm{~m}^{3} \mathrm{~s}^{-1}$ (compared to $12.65 \mathrm{~m}^{3} \mathrm{~s}^{-1}$ in calibration period). The lower performance of overall evaluation should be attributed to the insufficiency in storm rain days, especially for some extreme storm events in the summer of 2010 (see Fig. 9a). The underestimation of these events is likely due to inadequate observations of rainareas. It is widely acknowledged that the extreme runoff events are difficult to capture in alpine area, where gauged station is scarce, on the daily scale (Aizen et al., 2000; Jasper et al., 2002). However, the accuracy of our results is similar to Li and Williams 13409

\section{HESSD}

$11,13385-13441,2014$

Diagnostic

calibration of

a hydrological model

in an alpine area

Z. H. He et al.

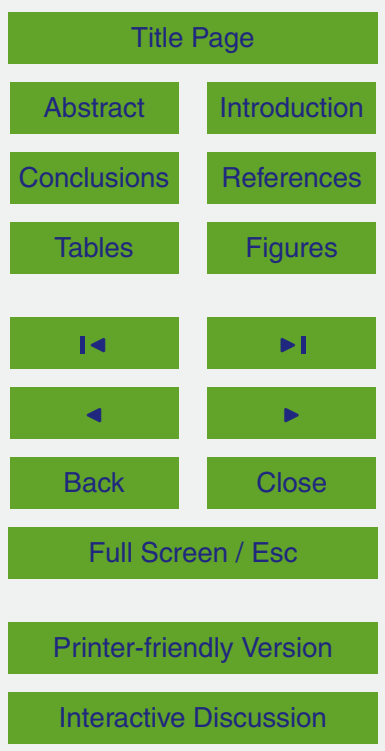

Interactive Discussion 
(2008) (used SRM model) and Liu et al. (2012) (who used the MIKE-SHE model) who performed similar work in a basin that is close to TRB in Tianshan Mountains. Their Nash values for daily discharge varied from 0.51 to 0.78 , and also failed to simulate the peak flows in summer. They also attributed the low efficiency to the heavy precipitation.

To further evaluate the robustness of the stepwise calibration method based on partitioning curves, cross validation was implemented. The hydrograph in the evaluation period was partitioned based on dominant runoff components, as was done in the calibration years 2003-2007. We calibrated the model to 2008-2012 and evaluated it for 2003-2007. The new calibrated parameter values are $\mathrm{KKA}=0.9, \mathrm{KKD}=0.003$, ${ }_{10} D_{\mathrm{s}}=2.2 \mathrm{~mm}^{\circ} \mathrm{C}^{-1} \mathrm{day}^{-1}, D_{\mathrm{g}}=7.4 \mathrm{~mm}^{\circ} \mathrm{C}^{-1} \mathrm{day}^{-1}$, WM $=10.2 \mathrm{~cm}$ and $B=0.77$, which are similar to the values calibrated in 2003-2007 listed in Table 4. The NSE, NSEIn and RMSE values for calibration period 2008-2012 and evaluation period 2003-2007 are $0.757,0.900,10.892 \mathrm{~m}^{3} \mathrm{~s}^{-1}$ and $0.883,0.910,8.589 \mathrm{~m}^{3} \mathrm{~s}^{-1}$, respectively, using this new calibrated parameter set. The simulations of the two periods by cross validation are presented in Fig. 9c and d, which shows similar performance by two calibrated parameter sets and further demonstrates the robustness of the proposed stepwise calibration method.

\subsection{Sensitivity analysis on index-based partitioning method}

The stepwise calibration method relies heavily on the hydrograph partition for different 20 runoff components. The indices defined in Sect. 3.1 are keys to identify the dominant days for melt water and rainwater. The definitions for elevation bands for the $0{ }^{\circ} \mathrm{C}$ Isotherm and for storm rain days in the year producing rainwater runoff should have significant influence on the parameter calibration. In this study, the elevation band of $0^{\circ} \mathrm{C}$ Isotherm for snowmelt is fixed and defined as $1650 \mathrm{~m}$. This value should have minimal effect on the snowmelt simulation, as the occurrence of snowmelt is actually determined by the MODIS snow cover data. Glacier cover area is assumed as constant, which is very rough for we have only one CGI data. In this section, we define different elevation bands of $0{ }^{\circ} \mathrm{C}$ Isotherm for glacier to analyze the effect of glacier

\section{HESSD}

11, 13385-13441, 2014
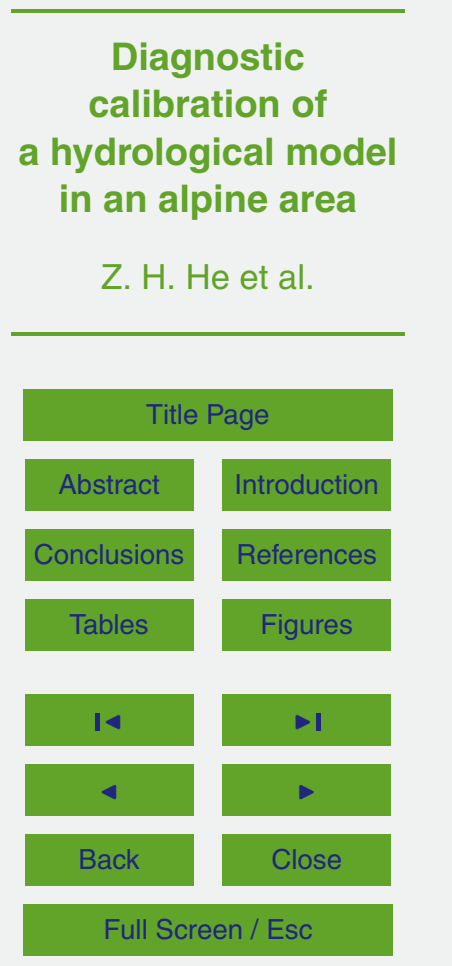

Printer-friendly Version

Interactive Discussion 
area variation on the model calibration. We also select different seasons as the storm rain period to analyze its sensitive effect.

According to the CGI data, the glacier area extends from the altitude of $2950 \mathrm{~m}$ in 2002. Considering the possible variability, we define four different lowest eleva5 tion bands for the glacier area (LEG), i.e. $-500 \mathrm{~m}(2450 \mathrm{~m}),-200 \mathrm{~m}(2750 \mathrm{~m}),+200 \mathrm{~m}$ $(3150 \mathrm{~m})$ and $+500 \mathrm{~m}(3450 \mathrm{~m})$. As an example, various hydrograph partition patterns in year 2003 are shown in Fig. 10. For the storm rain period (SRP), new seasons are defined as April to October, April to September, May to October, and June to August compared to the benchmark period May to September. A new hydrograph partition 10 pattern in year 2003 is also shown in Fig. 10. The left column in Fig. 10 shows that the $Q_{\mathrm{SB}}+Q_{\mathrm{SM}}+Q_{\mathrm{GM}}$ partition becomes longer while the $Q_{\mathrm{SB}}+Q_{\mathrm{SM}}$ partition becomes shorter when the LEG is lower. Therefore, glacier melt starts earlier and ends later in the years with lower LEG. In the right column, the $Q_{\mathrm{SB}}+Q_{\mathrm{SM}}+Q_{\mathrm{GM}}$ partition becomes longer with the shorter SRP, while the variation of the $Q_{\mathrm{SB}}+Q_{\mathrm{SM}}$ partition can be neg15 ligible. Parameters were re-calibrated according to the new partition curves, and the results are shown in Table 6, indicating the increase of degree-day factor for glacier melt $\left(D_{\mathrm{g}}\right)$ with the increase of the LEG. The value of $D_{\mathrm{g}}$ is also found to become higher when the SRP falls in the warmer months. The variation of LEG imposes significant impacts on the calibration of $D_{\mathrm{g}}$, with a result ranging from 5.8 to $8.0 \mathrm{~mm}^{\circ} \mathrm{C}^{-1}$ day $^{-1}$, a result ranging from 8.2 to $10.5 \mathrm{~cm}$. However, the calibration of parameter WM, with a result ranging from 8.2 to $10.5 \mathrm{~cm}$. However, the NSE values (see Table 6) for different settings show minimal differences. This can be attributed to the fact that parameters are optimized on separate partitioning curves in the stepwise calibration method. Each hydrograph partition can be well simulated by adjusting the parameter values. The partition patterns can influence the value of parameters significantly but only slightly influence the discharge simulation. Among various LEGs, the setting of $2950 \mathrm{~m}$ leads to the highest NSE value. Glacier melt degree day factor $\left(D_{\mathrm{g}}\right)$ calibrated with this LEG is $7.2 \mathrm{~mm}^{\circ} \mathrm{C}^{-1}$ day $^{-1}$, which is very close to the value estimated as $7.3 \mathrm{~mm}^{\circ} \mathrm{C}^{-1}$ day $^{-1}$ by Liu et al. (1999), in which the $D_{\mathrm{g}}$ is estimated according to the observed glacier

\section{HESSD}

$11,13385-13441,2014$
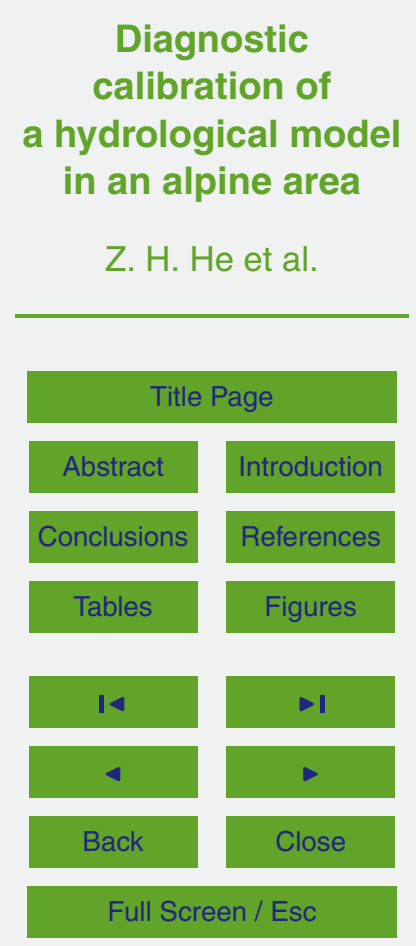

Printer-friendly Version

Interactive Discussion 
mass balance data in Tianshan area. This can further demonstrate the reasonability of the assumption in Sect. 3.2 that the glacier area is stable and its lowest elevation is fixed at $2950 \mathrm{~m}$ during the study period. For the various storm rain periods (SRP), when the May to October period is adopted, the discharge simulation is slightly better 5 than the benchmark setting of SRP, i.e. May to September. This phenomenon seems to indicate the importance of precipitation measurement as discussed in Sect. 4.4. With the help of more advanced precipitation measurement, the storm rain period can be determined more precisely to improve the model simulation.

To evaluate the relative dominance of multiple runoff components on the total runoff, 10 we compute their contributions to total runoff by various LEG and SRP in Fig. 11. The mean contributions of every runoff component are as follows: groundwater contributes $17 \%$, snow meltwater contributes $16.5 \%$, glacier meltwater contributes $40 \%$ and rainwater directly runoff contributes $26.5 \%$. Total melt water (snowmelt and glacier melt) occupies approximately $56.5 \%$ and is close to the ratio $63 \%$ suggested by Kang 15 et al. (1980).

\subsection{Sensitivity analysis on parameters}

The number of parameters to be calibrated is determined by the parameter sensitivity and a priori analysis. To evaluate the effect of different parameters on the simulation of different hydrograph partitions, we implemented a simple parameter sensitivity procedure that is carried out by a "one-at-a-time" approach. Parameters from different groups in Table 3 are selected for sensitivity analysis, including saturated hydraulic conductivity for u-zone $K_{\mathrm{u}}^{\mathrm{s}}$, saturated hydraulic conductivity for s-zone $K_{\mathrm{s}}^{\mathrm{s}}$, subsurface flow coefficient KKA and KKD, manning roughness coefficient for hillslope $n^{t}$, spatial heterogeneous coefficient for infiltration capacity $\alpha^{\mathrm{IFL}}$, ground surface depression stor25 age capacity $F \max ^{b}$, shape coefficient to calculate the saturation excess runoff area from the Xin'anjiang model $B$, spatial averaged tension water storage capacity in the Xin'anjiang model WM, glacier degree day factor $D_{\mathrm{g}}$ and snowmelt degree per day factor $D_{\mathrm{s}}$. Parameter are varied from -50 to $+50 \%$ of the calibrated values using the 13412

\section{HESSD}

$11,13385-13441,2014$
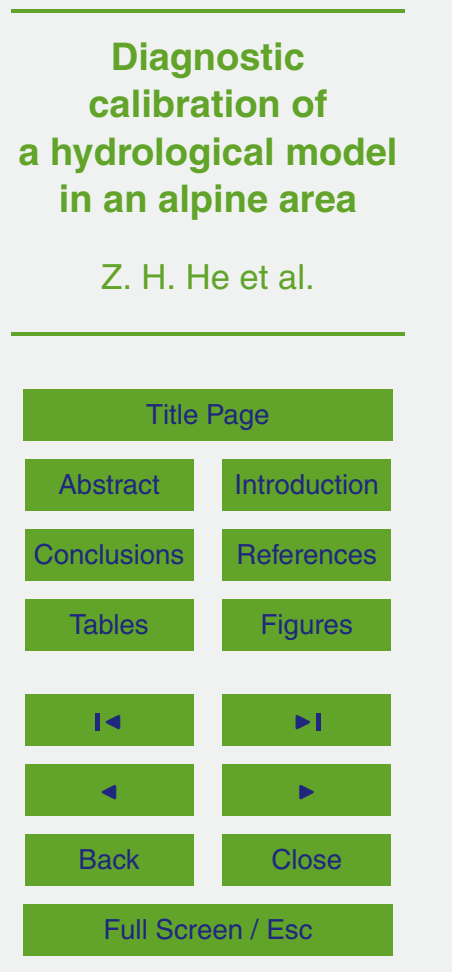

Printer-friendly Version

Interactive Discussion 
stepwise method in Table 4. The relative change $\left(R_{\mathrm{MS}}\right)$ of simulated measure merits (RMSEln or RMSE) for different hydrograph partitions are used to evaluate the sensitivity (Eq. 10), where MS is the value of measure merits by the calibrated parameter, $\mathrm{MS}_{+}$ is the merits value obtained by the parameter $+50 \%$ of the calibrated one, and MS_ is 5 the merits value obtained by the parameter $-50 \%$ of the calibrated one. The sensitivity simulation results are shown in Table 7 , which demonstrates the dominant control of parameter KKA, KKD, WM, $B, D_{\mathrm{s}}$ and $D_{\mathrm{g}}$. Some parameters have significant effects on simulation of multi hydrograph partitions. For example, parameters controlling the $Q_{\mathrm{SB}}+Q_{\mathrm{SM}}+Q_{\mathrm{GM}}+Q_{\mathrm{R}}$ period can also have significant effect on the other periods. To 10 minimize this interaction, iterative calibration was implemented in the calibration procedure. The number of calibrated parameters is determined as six, which control the main runoff components (i.e. groundwater baseflow, snowmelt, glacier melt and rainwater directly runoff). Note that the low dimension of parameter calibration should not account for the low efficiency of peak flow simulation, referring to the similar study in

15 Tianshan mountain areas by Li and Williams (2008), and Liu et al. (2012), in which the models have a higher parameter dimension (higher than six), and the peak flow simulations are still inadequate.

$R_{\mathrm{MS}}=\left|\frac{\mathrm{MS}_{+}-\mathrm{MS}_{-}}{\mathrm{MS}}\right| \times 100 \%$

\section{Summary and conclusion}

20 This study proposes diagnostic calibration approach to extracting index information from available data series in an alpine area, which can be further used to partition the hydrograph into dominant runoff components. The parameters of a hydrological model were grouped according to runoff generation mechanism and then related to the corresponding hydrologic partitioning curve. Each parameter group was calibrated to improve the simulation of the corresponding partitioning curve in a stepwise way. In
HESSD

$11,13385-13441,2014$

Diagnostic

calibration of

a hydrological model

in an alpine area

Z. H. He et al.

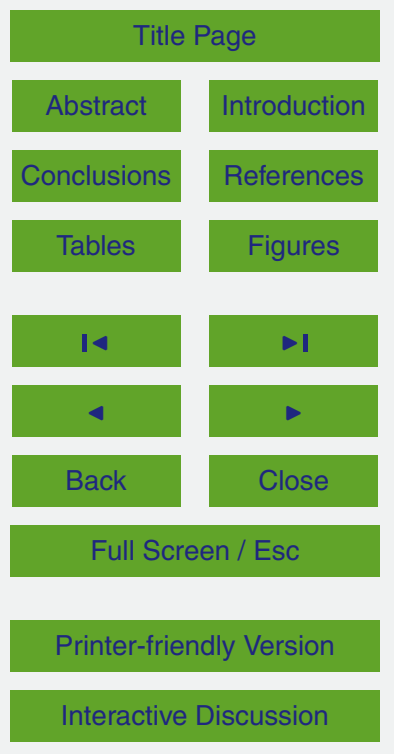


this way, the dimension of measurement information is expanded to equal the number of parameter groups. The parameter uncertainty due to interaction of parameters is reduced via an iterative calibration procedure. Application to an alpine watershed in the Tianshan Mountain in northwestern China showed that the approach performed 5 reasonably well. Cross validation and comparison to an automatic calibration method indicated its robustness.

Note that a semi-distributed hydrological model was utilized to illustrate the proposed diagnostic calibration approach in the high mountainous Tailan River basin. Glacier mass balance is not simulated in the model and the glacier coverage was kept fixed 10 during the study period, which can be subject to significant change in the context of global warming. According to existing studies (Stahl et al., 2008; Schaefli and Huss, 2011; Jost et al., 2012), glacier mass balance data is useful to constrain the parameter uncertainty for hydrological modeling in a glaciered basin. While arguing that our assumption of unchanged glacier coverage will not weaken the importance of the proposed approach, we acknowledge that an improved model coupled with glacier mass balance equations will improve the accuracy of hydrological simulation aided by glacier mass balance observations. This is left for future research.

A prerequisite for the proposed approach is hydrograph partitioning based on dominant runoff components. The key to the partition procedure is to identify the functional domain of each runoff component from signature information extracted from easily available data. A partition can be achieved in which the relative roles of different runoff components in the basin runoff vary significantly with time. The alpine watershed is an area in which the runoff components can be separated by the combination of topography, ground-gauged temperature and precipitation, and remotely sensed snow and glacier coverage. Other areas with strong temporal variability of catchment wetness along with precipitation (e.g. monsoon zones) could also be suitable for the proposed approach. The Dunne runoff is prone to dominate the hydrograph when the catchment is wet and it could switch to Hortonian runoff rapidly under the combination of high
HESSD

$11,13385-13441,2014$
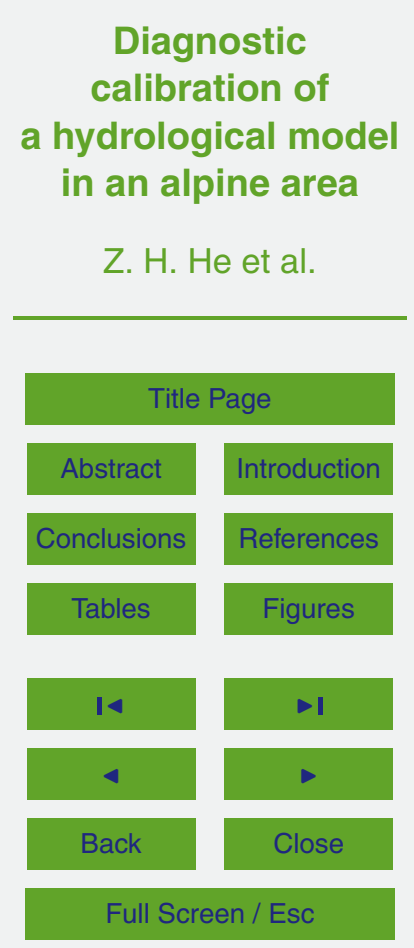

Printer-friendly Version

Interactive Discussion 
evaporative demand and less precipitation, as shown by Tian et al. (2012) in the Blue River basin of Oklahoma. This is, however, also left for future research.

Acknowledgements. We wish to thank Wang Xinhui for his assistance in collecting hydrometeorology data in the Tailan River basin, and thank Charlie Luce and Viviana López-Burgos 5 who provided great help in MODIS snow coverage product filtering. The authors would also like to thank sincerely two Referees (B. Schaefli and M. Zappa) and Editor Markus Weiler for his careful comments, which improve the quality of manuscript significantly. This study was supported by the National Science Foundation of China (NSFC 51190092, U1202232, 51222901) and the foundation of the State Key Laboratory of Hydroscience and Engineering of Tsinghua

\section{References}

Ackerman, S. A., Strabala, K. I., Menzel, W. P., Frey, R. A., Moeller, C. C., and Gumley, L. E.: Discriminating clear sky from clouds with MODIS, J. Geophys. Res., 103, 32141-32157, 1998.

Aizen, V., Aizen, E., Glazirin, G., and Loaiciga, H. A.: Simulation of daily runoff in Central Asian alpine watersheds, J. Hydrol., 238, 15-34, 2000.

Akyurek, Z., Surer, S., and Beser, O.: Investigation of the snow-cover dynamics in the Upper Euphrates Basin of Turkey using remotely sensed snow-cover products and hydrometeorological data, Hydrol. Process., 25, 3637-3648, 2011.

20 Arnold, J. G. and Allen, P. M.: Automated methods for estimating baseflow and ground water recharge from streamflow records, J. Am. Water Resour. As., 35, 411-424, 1999.

Arnold, J. G., Allen, P. M., Muttiah, R., and Bernhardt, G.: Automated base-flow separation and recession analysis techniques, Ground Water, 33, 1010-1018, 1995.

Beven, K.: Prophecy, reality and uncertainty in distributed hydrological modelling, Adv. Water Resour., 16, 41-51, 1993.

Beven, K.: Equifinality and uncertainty in geomorphological modelling, The Scientific Nature of Geomorphology: Proceedings of the 27th Binghamton Symposium in Geomorphology, Chichester, UK, 289-313, 1996.

Beven, K. and Binley, A.: The future of distributed models: model calibration and uncertainty

HESSD

$11,13385-13441,2014$

Diagnostic

calibration of

a hydrological model

in an alpine area

Z. H. He et al.

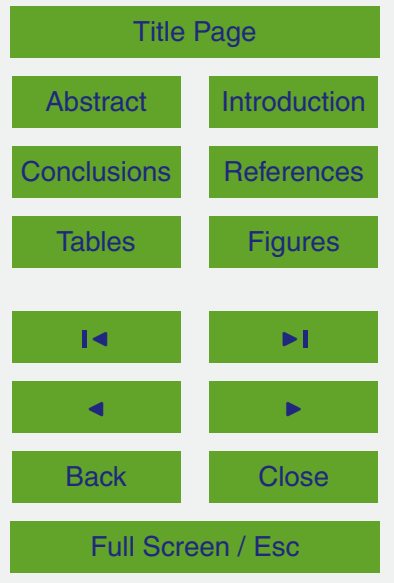

Printer-friendly Version

Interactive Discussion 
Beven, K. and Freer, J.: Equifinality, data assimilation, and uncertainty estimation in mechanistic modelling of complex environmental systems using the GLUE methodology, J. Hydrol., 249, 11-29, 2001.

Blöschl, G., Sivapalan, M., Wagener, T., Viglione, A., and Savenije, H. (Eds.): Runoff Prediction in Ungauged Basins: Synthesis Across Processes, Places and Scales, Cambridge Univ. Press, New York, 2013.

Boyle, D. P., Gupta, H. V., and Sorooshian, S.: Toward improved calibration of hydrologic models: combining the strengths of manual and automatic methods, Water Resour. Res., 36, 3663-3674, 2000.

10 Brazil, L.: Multilevel calibration strategy for complex hydrologic simulation models, NOAA Technical Report, NWS 42, Fort Collins, 217 pp., 1989.

Bulygina, N., Mclntyre, N., and Wheater, H.: Conditioning rainfall-runoff model parameters for ungauged catchments and land management impacts analysis, Hydrol. Earth Syst. Sci., 13, 893-904, doi:10.5194/hess-13-893-2009, 2009.

Daly, S. F., Davis, R., Ochs, E., and Pangburn, T.: An approach to spatially distributed snow modelling of the Sacramento and San Joaquin basins, California, Hydrol. Process., 14, 3257-3271, 2000.

Deb, K., Pratap, A., Agarwal, S., and Meyarivan, T.: A fast and elitist multiobjective genetic algorithm: NSGA-II, IEEE T. Evolut. Comput., 6, 182-197, 2002.

20 Detenbeck, N. E., Brady, V. J., Taylor, D. L., Snarski, V. M., and Batterman, S. L.: Relationship of stream flow regime in the western Lake Superior basin to watershed type characteristics, J. Hydrol., 309, 258-276, 2005.

Duan, Q., Sorooshian, S., and Gupta, V.: Effective and efficient global optimization for conceptual rainfall-runoff models, Water Resour. Res., 28, 1015-1031, 1992.

Dunn, S. M. and Colohan, R. J. E.: Developing the snow component of a distributed hydrological model: a step-wise approach based on multi-objective analysis, J. Hydrol., 223, 1-16, 1999.

Eder, G., Fuchs, M., Nachtnebel, H., and Loibl, W.: Semi-distributed modelling of the monthly water balance in an alpine catchment, Hydrol. Process., 19, 2339-2360, 2005.

Farmer, D., Sivapalan, M., and Jothityangkoon, C.: Climate, soil, and vegetation controls upon the variability of water balance in temperate and semiarid landscapes: downward approach to water balance analysis, Water Resour. Res., 39, 1035, doi:10.1029/2001WR000328, 2003.

Fierz, C., Riber, P., Adams, E., Curran, A., Fohn, P., Lehning, M., and Pluss, C.: Evaluation of snow-surface energy balance models in alpine terrain, J. Hydrol., 282, 76-94, 2003.
HESSD

$11,13385-13441,2014$

Diagnostic

calibration of

a hydrological model

in an alpine area

Z. H. He et al.

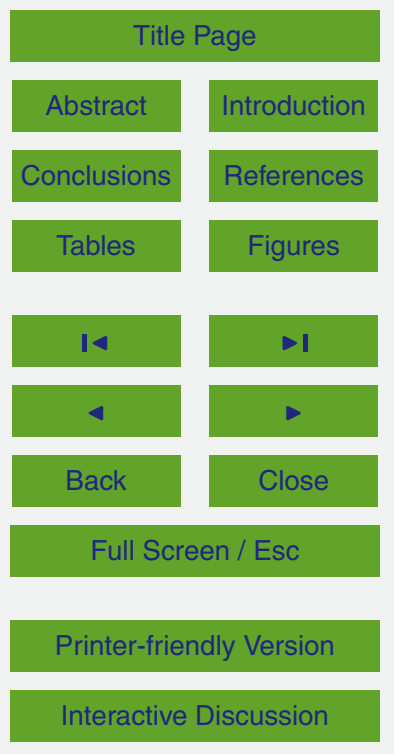

13416 
Gafurov, A. and Bárdossy, A.: Cloud removal methodology from MODIS snow cover product, Hydrol. Earth Syst. Sci., 13, 1361-1373, doi:10.5194/hess-13-1361-2009, 2009.

Gan, T. Y. and Biftu, G. F.: Automatic calibration of conceptual rainfall-runoff models: optimization algorithms, catchment conditions, and model structure, Water Resour. Res., 32, $5 \quad 3513-3524,1996$.

Gao, W., Li, Z., and Zhang, M.: Study on particle-size properties of suspended load in glacier runoff from the Tomor Peak, Arid Zone Res., 28, 449-454, 2011.

Gomez-Landesa, E. and Rango, A.: Operational snowmelt runoff forecasting in the Spanish Pyrenees using the snowmelt runoff model, Hydrol. Process., 16, 1583-1591, 2002.

10 Gupta, H. V., Sorooshian, S., and Yapo, P. O.: Toward improved calibration of hydrologic models: multiple and noncommensurable measures of information, Water Resour. Res., 34, 751-763, 1998.

Gupta, H. V., Wagener, T., and Liu, Y.: Reconciling theory with observations: elements of a diagnostic approach to model evaluation, Hydrol. Process., 22, 3802-3813, 2008.

Gupta, H. V., Kling, H., Yilmaz, K. K., and Martinez, G. F.: Decomposition of the mean squared error and NSE performance criteria: implications for improving hydrological modelling, J. Hydrol., 377, 80-91, 2009.

Gupta, V. K. and Sorooshian, S.: Uniqueness and observability of conceptual rainfall-runoff model parameters: the percolation process examined, Water Resour. Res., 19, 269-276, $20 \quad 1983$

Gupta, V. K. and Sorooshian, S.: The automatic calibration of conceptual catchment models using derivative-based optimization algorithms, Water Resour. Res., 21, 437-485, 1985.

Gurtz, J., Baltensweiler, A., and Lang, H.: Spatially distributed hydrotope-based modelling of evapotranspiration and runoff in mountainous basins, Hydrol. Process., 13, 2751-2768, 251999.

Haberlandt, U., Klocking, B., Krysanova, V., and Becker, A.: Regionalisation of the base flow index from dynamically simulated flow components - a case study in the Elbe River Basin, J. Hydrol., 248, 35-53, 2001.

Hingray, B., Schaefli, B., Mezghani, A., and Hamdi, Y.: Signature-based model calibration for 30 hydrological prediction in mesoscale Alpine catchments, Hydrolog. Sci. J., 55, 1002-1016, 2010.

Hock, R.: Temperature index melt modelling in mountain areas, J. Hydrol., 282, 104-115, 2003.

\section{HESSD}

$11,13385-13441,2014$

\section{Diagnostic \\ calibration of \\ a hydrological model \\ in an alpine area \\ Z. H. He et al.}

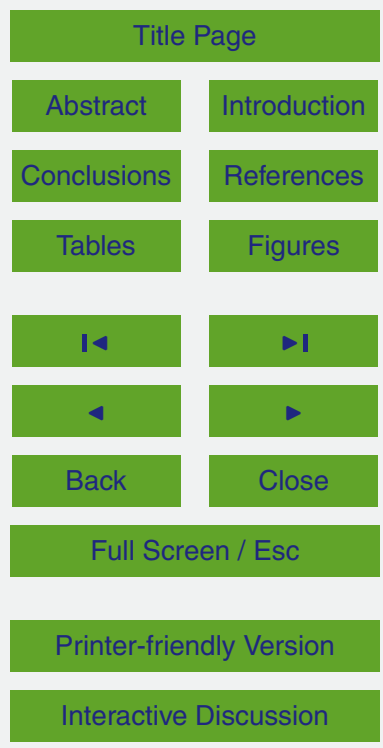

Interactive Discussion 
Hooper, R. P. and Shoemaker, C. A.: A Comparison of Chemical and Isotopic Hydrograph Separation, Water Resour. Res., 22, 1444-1454, 1986.

Howard, C.: Revisiting the degree-day method for snowmelt computations - discussion, Water Resour. Bull., 32, 411-413, 1996.

5 Huss, M., Farinotti, D., Bauder, A., and Funk, M.: Modelling runoff from highly glacierized alpine drainage basins in a changing climate, Hydrol. Process., 22, 3888-3902, 2008.

Jasper, K., Gurtz, J., and Herbert, L.: Advanced flood forecasting in Alpine watersheds by coupling meteorological observations and forecasts with a distributed hydrological model, $\mathrm{J}$. Hydrol., 267, 40-52, 2002.

10 Jiang, H. F.: Snow ablation modeling and its application to Qiedeke basin, J. Xinjiang Agric. Univ., 1, 67-75, 1987.

Johnston, P. R. and Pilgrim, D. H.: Parameter optimization for watershed models, Water Resour. Res., 12, 477-486, 1976.

Jost, G., Moore, R. D., Menounos, B., and Wheate, R.: Quantifying the contribution of glacier 15 runoff to streamflow in the upper Columbia River Basin, Canada, Hydrol. Earth Syst. Sci., 16, 849-860, doi:10.5194/hess-16-849-2012, 2012.

Jothityangkoon, C., Sivapalan, M., and Farmer, D. L.: Process controls of water balance variability in a large semi-arid catchment: downward approach to hydrological model development, J. Hydrol., 254, 174-198, 2001.

20 Juston, J., Seibert, J., and Johansson, P.: Temporal sampling strategies and uncertainty in calibrating a conceptual hydrological model for a small boreal catchment, Hydrol. Process., 23, 3093-3109, 2009.

Kane, D. L., Gieck, R. E., and Hinzman, L. D.: Snow modeling at small Alaskan Arctic Watershed, J. Hydrol. Eng., 2, 204-210, 1997.

Kang, E., Zhu, S., and Huang, M.: Some results of the research on glacial hydrology in the region of MT. Tuomuer, J. Glaciol. Geocryol., 2, 18-21, 1980

Klok, E. J., Jasper, K., Roelofsma, K. P., Gurtz, J., and Badoux, A.: Distributed hydrological modelling of a heavily glaciated Alpine river basin, Hydrolog. Sci. J., 46, 553-570, 2001.

Kollat, J. B. and Reed, P. M.: Comparing state-of-the-art evolutionary multi-objective algorithms for long-term groundwater monitoring design, Adv. Water Resour., 29, 792-807, 2006.

Li, H. Y., Sivapalan, M., and Tian, F. Q.: Comparative diagnostic analysis of runoff generation processes in Oklahoma DMIP2 basins: the Blue River and the Illinois River, J. Hydrol., 418, 90-109, 2012.

HESSD

11, 13385-13441, 2014

Diagnostic

calibration of

a hydrological model

in an alpine area

Z. H. He et al.

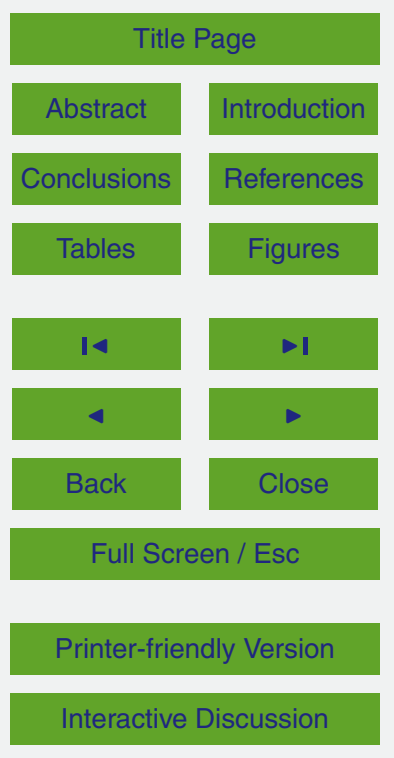

(i) 
$\mathrm{Li}, \mathrm{X}$. G. and Williams, M. W.: Snowmelt runoff modelling in an arid mountain watershed, Tarim Basin, China, Hydrol. Process., 22, 3931-3940, 2008.

Liu, D. F., Tian, F. Q., Hu, H. C., and Hu, H. P.: The role of run-on for overland flow and the characteristics of runoff generation in the Loess Plateau, China, Hydrolog. Sci. J., 57, 11071117, 2012.

Liu, S. Y., Xie, Z. C., Wang, N. L., and Ye, B. S.: Mass balance sensitivity to climate change: a case study of glacier no. 1 at Urumqi riverhead, Tianshan mountains, China, Chin. Geogr. Sci., 9, 134-140, 1999.

Liu, T., Willems, P., Feng, X. W., Li, Q., Huang, Y., Bao, A. M., Chen, X., Veroustraete, F., and Dong, Q. H.: On the usefulness of remote sensing input data for spatially distributed hydrological modelling: case of the Tarim River basin in China, Hydrol. Process., 26, 335344, 2012.

López-Burgos, V., Gupta, H. V., and Clark, M.: Reducing cloud obscuration of MODIS snow cover area products by combining spatio-temporal techniques with a probability of snow approach, Hydrol. Earth Syst. Sci., 17, 1809-1823, doi:10.5194/hess-17-1809-2013, 2013.

Luo, Y., Arnold, J., Liu, S., Wang, X., and Chen, X.: Inclusion of glacier processes for distributed hydrological modeling at basin scale with application to a watershed in Tianshan Mountains, northwest China, J. Hydrol., 477, 72-85, 2013.

Martinec, J., Oeschger, H., Schotterer, U., and Siegenthaler, U.: Snowmelt and groundwater storage in alpine basin, in: Hydrological Aspects of Alpine and High Mountain Areas, IAHS Press, Wallingford, UK, 169-175, 1982.

McCuen, R. H.: Hydrologic Analysis and Design, Prentice Hall, New Jersey, 355-360, 1989.

Mendoza, G. F., Steenhuis, T. S., Walter, M. T., and Parlange, J. Y.: Estimating basin-wide hydraulic parameters of a semi-arid mountainous watershed by recession-flow analysis, $\mathrm{J}$. Hydrol., 279, 57-69, 2003.

Mou, L., Tian, F., Hu, H., and Sivapalan, M.: Extension of the Representative Elementary Watershed approach for cold regions: constitutive relationships and an application, Hydrol. Earth Syst. Sci., 12, 565-585, doi:10.5194/hess-12-565-2008, 2008.

Mu, Z. X. and Jiang, H. F.: Establishment of snowmelt type Xin'anjiang watershed model based on digital elevation model, J. Xinjiang Agric. Univ., 5, 75-80, 2009.

Nash, J. E. and Sutcliffe, J. V.: River flow forecasting through conceptual models part I - A discussion of principles, J. Hydrol., 10, 282-290, 1970.

\section{Diagnostic \\ calibration of \\ a hydrological model \\ in an alpine area \\ Z. H. He et al.}

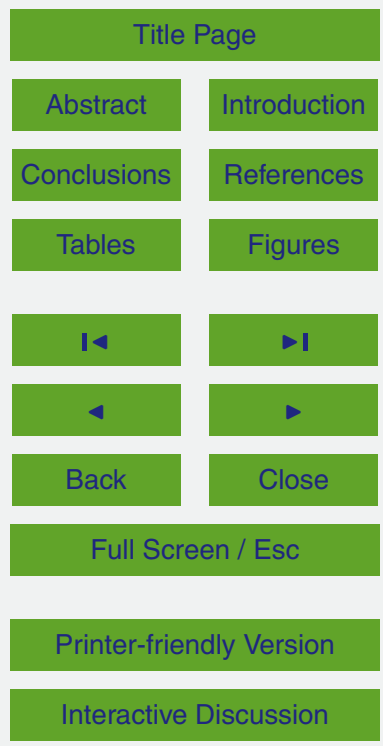


Nathan, R. J. and McMahon, T. A.: Evaluation of automated techniques for base flow and recession analyses, Water Resour. Res., 26, 1465-1473, 1990.

Nejadhashemi, A. P., Shirmohammadi, A., Sheridan, J. M., Montas, H. J., and Mankin, K. R.: Case study: evaluation of streamflow partitioning methods, J. Irrigat. Drain. Eng., 135, 791801, 2009.

Pellicciotti, F., Brock, B., Strasser, U., Burlando, P., Funk, M., and Corripio, J.: An enhanced temperature-index glacier melt model including the shortwave radiation balance: development and testing for Haut Glacier d'Arolla, Switzerland, J. Glaciol., 51, 573-587, 2005.

Pinder, G. F. and Jones, J. F.: Determination of the ground-water component of peak Determination of the ground-water component of peak discharge from the chemistry of total runoff, Water Resour. Res., 5, 438-445, 1969.

Rango, A. and Martinec, J.: Application of a snowmelt-runoff model using landsat data, Nord. Hydrol., 10, 225-238, 1979.

Richter, B. D., Baumgartner, J. V., Powell, J., and Braun, D. P.: A method for assessing hydro15 logic alteration within ecosystems, Conserv. Biol., 10, 1163-1174, 1996.

Schaefli, B. and Gupta, H. V.: Do Nash values have value, Hydrol. Process., 21, 2075-2080, 2007.

Schaefli, B. and Huss, M.: Integrating point glacier mass balance observations into hydrologic model identification, Hydrol. Earth Syst. Sci., 15, 1227-1241, doi:10.5194/hess-15-12272011, 2011.

Schaefli, B., Hingray, B., Niggli, M., and Musy, A.: A conceptual glacio-hydrological model for high mountainous catchments, Hydrol. Earth Syst. Sci., 9, 95-109, doi:10.5194/hess-9-952005, 2005.

Shamir, E., Imam, B., Gupta, H. V., and Sorooshian, S.: Application of temporal streamflow descriptors in hydrologic model parameter estimation, Water Resour. Res., 41, W06021, doi:10.1029/2004WR003409, 2005a.

Shamir, E., Imam, B., Morin, E., Gupta, H. V., and Sorooshian, S.: The role of hydrograph indices in parameter estimation of rainfall-runoff models, Hydrol. Process., 19, 2187-2207, 2005b.

30 Shen, Y., Liu, S., Ding, Y., and Wang, S.: Glacier mass balance change in Tailanhe River Watersheds on the south slope of the Tianshan Mountains and its impact on water resources, J. Glaciol. Geocryol., 25, 124-129, 2003.
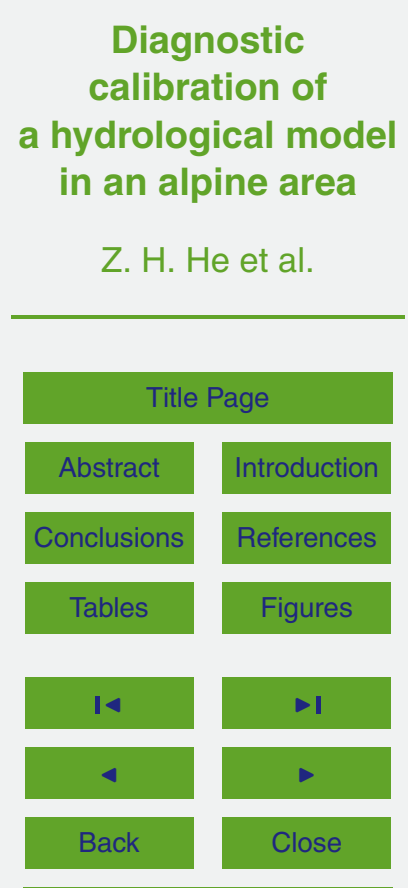

Full Screen / Esc

Printer-friendly Version

Interactive Discussion

\section{0}


Shi, Y.: Concise Glacier Inventory of China, Shanghai Popular Science Press, Shanghai, China, 2008.

Singh, P., Kumar, N., and Arora, M.: Degree-day factors for snow and ice for Dokriani Glacier, Garhwal Himalayas, J. Hydrol., 235, 1-11, 2000.

5 Sivapalan, M., Bloschl, G., Zhang, L., and Vertessy, R.: Downward approach to hydrological prediction, Hydrol. Process., 17, 2101-2111, 2003.

Sorooshian, S. and Gupta, V. K.: Automatic calibration of conceptual rainfall-runoff modelsthe question of parameter observability and uniqueness, Water Resour. Res., 19, 260-268, 1983.

10 Spear, R. C. and Hornberger, G. M.: Eutrophication in peel inlet - II. Identification of critical uncertainties via generalized sensitivity analysis, Water Res., 14, 43-49, 1980.

Stahl, K., Moore, R. D., Shea, J. M., Hutchinson, D., and Cannon, A. J.: Coupled modelling of glacier and streamflow response to future climate scenarios, Water Resour. Res., 44, W02422, doi:10.1029/2007WR005956, 2008.

Sun, M., Yao, X., Li, Z., and Li, J.: Estimation of Tailan River discharge in the Tianshan Mountains in the 21st Century, Adv. Clim. Change Res., 8, 342-349, 2012.

Swamy, A. N. and Brivio, P. A.: Modelling runoff using optical satellite remote sensing data in a high mountainous alpine catchment of Italy, Hydrol. Process., 11, 1475-1491, 1997.

Tabony, R. C.: The variation of surface temperature with altitude, Meteorol. Mag., 114, 37-48, 1985.

Tahir, A. A., Chevallier, P., Arnaud, Y., Neppel, L., and Ahmad, B.: Modeling snowmelt-runoff under climate scenarios in the Hunza River basin, Karakoram Range, Northern Pakistan, J. Hydrol., 409, 104-117, 2011.

Tian, F., Hu, H., Lei, Z., and Sivapalan, M.: Extension of the Representative Elementary Watershed approach for cold regions via explicit treatment of energy related processes, Hydrol. Earth Syst. Sci., 10, 619-644, doi:10.5194/hess-10-619-2006, 2006.

Tian, F. Q., Hu, H. P., and Lei, Z. D.: Thermodynamic watershed hydrological model: constitutive relationship, Sci. China Ser. E, 51, 1353-1369, 2008.

Tian, F. Q., Li, H. Y., and Sivapalan, M.: Model diagnostic analysis of seasonal switching of 30 runoff generation mechanisms in the Blue River basin, Oklahoma, J. Hydrol., 418, 136-149, 2012.

Van Griensven, A. and Bauwens, W.: Multiobjective autocalibration for semidistributed water quality models, Water Resour. Res., 39, 1348, doi:10.1029/2003WR002284, 2003.

Diagnostic

calibration of

a hydrological model

in an alpine area

Z. H. He et al.

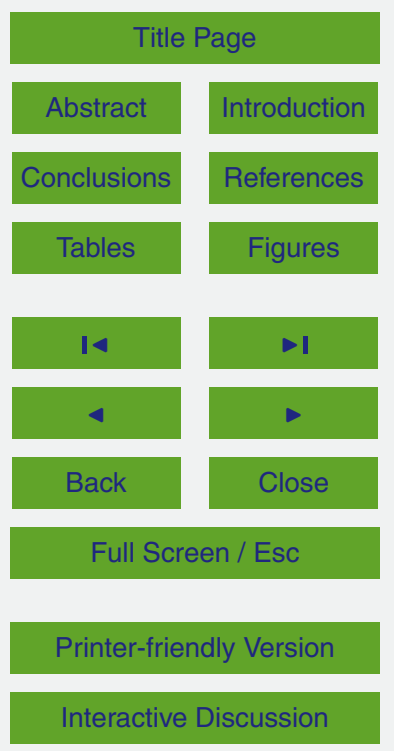

Interactive Discussion 
Van Straten, G. T. and Keesman, K. J.: Uncertainty propagation and speculation in projective forecasts of environmental change: a lake-eutrophication example, J. Forecast, 10, 163-190, 1991.

Vivoni, E. R., Entekhabi, D., Bras, R. L., and Ivanov, V. Y.: Controls on runoff generation and 5 scale-dependence in a distributed hydrologic model, Hydrol. Earth Syst. Sci., 11, 1683-1701, doi:10.5194/hess-11-1683-2007, 2007.

Vrugt, J. A., Gupta, H. V., Bastidas, L. A., Bouten, W., and Sorooshian, S.: Effective and efficient algorithm for multiobjective optimization of hydrologic models, Water Resour. Res., 39, 1214, doi:10.1029/2002WR001746, 2003a.

10 Vrugt, J. A., Gupta, H. V., Bouten, W., and Sorooshian, S.: A shuffled complex evolution metropolis algorithm for optimization and uncertainty assessment of hydrological model parameters, Water Resour. Res., 39, 1201, doi:10.1029/2002WR001642, 2003b.

Wang, X. W., Xie, H. J., Liang, T. G., and Huang, X. D.: Comparison and validation of MODIS standard and new combination of Terra and Aqua snow cover products in northern Xinjiang, China, Hydrol. Process., 23, 419-429, 2009.

Westerberg, I. K., Guerrero, J.-L., Younger, P. M., Beven, K. J., Seibert, J., Halldin, S., Freer, J. E., and Xu, C.-Y.: Calibration of hydrological models using flow-duration curves, Hydrol. Earth Syst. Sci., 15, 2205-2227, doi:10.5194/hess-15-2205-2011, 2011.

$\mathrm{Wu}, \mathrm{J}$. and Li, L.: A rain-on-snow mixed flood forecast model and its application, Engin. J. Wuhan Univ., 40, 20-23, 2007.

Xie, C., Ding, Y., Liu, S., and Han, H.: Analysis on the glacial hydrological features of the glaciers on the south slope of Mt. Tuomuer and the effects on runoff, Arid Land Geogr., 27, 570-575, 2004.

Yadav, M., Wagener, T., and Gupta, H.: Regionalization of constraints on expected watershed response behavior for improved predictions in ungauged basins, Adv. Water Resour., 30, 1756-1774, 2007.

Yang, D. Q., Zhao, Y. Y., Armstrong, R., Robinson, D., and Brodzik, M. J.: Streamflow response to seasonal snow cover mass changes over large Siberian watersheds, J. Geophys. Res., 112, F02S22, doi:10.1029/2006JF000518, 2007.

so Yang, X. S., Jiang, H. F., Huang, C. R. Zheng, Z., and Yong, G.: An applied study on the snowmelt type of Xin'anjiang watershed model at the Kaidu River basin, J. Xinjiang Agric. Univ., 4, 82-90, 1987.
HESSD

11, 13385-13441, 2014

Diagnostic

calibration of

a hydrological model

in an alpine area

Z. H. He et al.

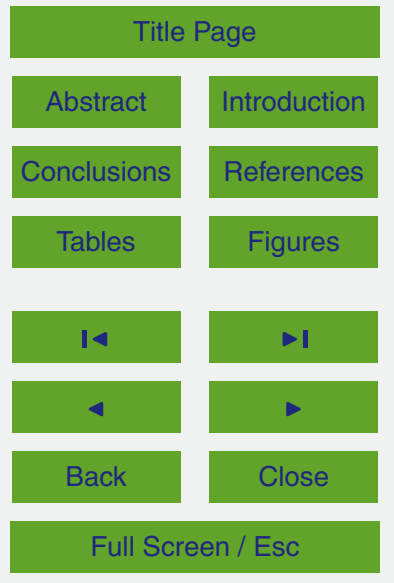

Printer-friendly Version

Interactive Discussion 
Yilmaz, K. K., Gupta, H. V., and Wagener, T.: A process-based diagnostic approach to model evaluation: application to the NWS distributed hydrologic model, Water Resour. Res., 44, W09417, doi:10.1029/2007WR006716, 2008.

Zhang, Z. X., Wagener, T., Reed, P., and Bhushan, R.: Reducing uncertainty in predictions 5 in ungauged basins by combining hydrologic indices regionalization and multiobjective optimization, Water Resour. Res., 44, W00B04, doi:10.1029/2008WR006833, 2008.

Zhao, R. J.: The Xin'anjiang model applied in China, J. Hydrol., 135, 371-381, 1992.

\section{Diagnostic}

calibration of

a hydrological model

in an alpine area

Z. H. He et al.

Title Page

Abstract

Introduction

Conclusions

References

Tables

Figures

14

Back

Full Screen / Esc

Printer-friendly Version

Interactive Discussion 
Table 1. Estimated monthly temperature lapse rate in the TRB.

\begin{tabular}{lc}
\hline Month & $\begin{array}{r}\text { Temperature lapse rate } \\
\left({ }^{\circ} \mathrm{C} \text { day }^{-1} 100 \mathrm{~m}^{-1}\right)\end{array}$ \\
\hline Jan & -0.38 \\
Feb & -0.38 \\
Mar & -0.66 \\
Apr & -0.76 \\
May & -0.80 \\
Jun & -0.78 \\
Jul & -0.82 \\
Aug & -0.86 \\
Sep & -0.66 \\
Oct & -0.60 \\
Nov & -0.54 \\
Dec & -0.30 \\
Annual & -0.62 \\
\hline
\end{tabular}

\section{HESSD}

$11,13385-13441,2014$

\section{Diagnostic} calibration of

a hydrological model in an alpine area

Z. H. He et al.

Title Page

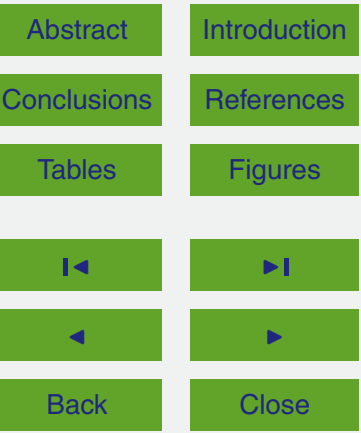

Full Screen / Esc

Printer-friendly Version

Interactive Discussion 
Table 2. Estimated week-precipitation lapse rate in storm rain months.

\begin{tabular}{lc}
\hline Month & $\begin{array}{c}\text { Precipitation lapse rate } \\
\left(\mathrm{mm} \mathrm{week}^{-1} 100 \mathrm{~m}^{-1}\right)\end{array}$ \\
\hline May & 1.63 \\
Jun & 1.69 \\
Jul & 3.14 \\
Aug & 2.40 \\
Sep & 2.28 \\
\hline
\end{tabular}

HESSD

$11,13385-13441,2014$

Diagnostic calibration of

a hydrological model in an alpine area

Z. H. He et al.

Title Page

Abstract

Introduction

Conclusions References

Tables

Figures

14

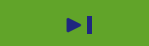

4

Back

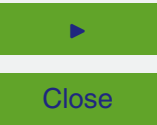

Full Screen / Esc

Printer-friendly Version

Interactive Discussion 
Table 3. Grouped parameters in the THREW model. Parameters subjected to calibration are highlighted in bold.

\begin{tabular}{|c|c|c|c|c|}
\hline Category & Symbol & Unit & Description & Value \\
\hline \multirow[t]{4}{*}{ Subsurface } & $K_{\mathrm{s}}^{\mathrm{u}}$ & $\mathrm{ms}^{-1}$ & $\begin{array}{l}\text { Saturated hydraulic } \\
\text { conductivity for u-zone }\end{array}$ & $1.25 \mathrm{E}-05$ \\
\hline & $K_{\mathrm{s}}^{\mathrm{s}}$ & $\mathrm{ms}^{-1}$ & $\begin{array}{l}\text { Saturated hydraulic } \\
\text { conductivity for s-zone }\end{array}$ & $1.25 \mathrm{E}-05$ \\
\hline & KKA & - & $\begin{array}{l}\text { Coefficient used to calculate } \\
\text { subsurface flow }\end{array}$ & Calibrated \\
\hline & KKD & - & $\begin{array}{l}\text { Coefficient used to calculate } \\
\text { subsurface flow }\end{array}$ & Calibrated \\
\hline \multirow[t]{2}{*}{ Routing } & $n^{t}$ & - & $\begin{array}{l}\text { Manning roughness coefficient } \\
\text { for hillslope, obtained from } \\
\text { the literature according to } \\
\text { land use and vegetation type }\end{array}$ & $1.50 \mathrm{E}-01$ \\
\hline & $n^{r}$ & - & $\begin{array}{l}\text { Similar to } n^{\dagger} \text {, roughness } \\
\text { coefficient for channel }\end{array}$ & $3.00 E-01$ \\
\hline \multirow[t]{2}{*}{ Infiltration } & $\alpha^{\mathrm{EFL}}$ & - & $\begin{array}{l}\text { Spatial heterogeneous coefficient } \\
\text { for exfiltration capacity }\end{array}$ & $1.00 \mathrm{E}+00$ \\
\hline & $\alpha^{\mathrm{IFL}}$ & - & $\begin{array}{l}\text { Spatial heterogeneous coefficient } \\
\text { for infiltration capacity }\end{array}$ & $1.50 \mathrm{E}+00$ \\
\hline \multirow[t]{2}{*}{ Interception } & $F \max ^{b}$ & $\mathrm{~m}$ & $\begin{array}{l}\text { Ground surface depression } \\
\text { storage capacity }\end{array}$ & $0.00 E+00$ \\
\hline & $\alpha^{\mathrm{vb}}$ & $\mathrm{m}$ & $\begin{array}{l}\text { Maximum rainfall depth a single } \\
\text { leaf can intercept and hold }\end{array}$ & $1.00 \mathrm{E}-05$ \\
\hline \multirow[t]{2}{*}{$\begin{array}{l}\text { Rainfall } \\
\text { runoff }\end{array}$} & $B$ & - & $\begin{array}{l}\text { Shape coefficient to calculate } \\
\text { the saturation excess runoff } \\
\text { area from the Xin'anjiang model }\end{array}$ & Calibrated \\
\hline & WM & cm & $\begin{array}{l}\text { Spatial averaged tension water } \\
\text { storage capacity in the Xin'anjiang } \\
\text { model }\end{array}$ & Calibrated \\
\hline Melt & $\begin{array}{l}D_{\mathrm{g}} \\
D_{\mathrm{s}}\end{array}$ & $\begin{array}{l}\mathrm{mm}^{\circ} \mathrm{C}^{-1} \mathrm{day}^{-1} \\
\mathrm{~mm}^{\circ} \mathrm{C}^{-1} \text { day }^{-1}\end{array}$ & $\begin{array}{l}\text { Glacier melt degree day factor } \\
\text { Snowmelt degree day factor }\end{array}$ & $\begin{array}{l}\text { Calibrated } \\
\text { Calibrated }\end{array}$ \\
\hline
\end{tabular}

Diagnostic

calibration of

a hydrological model

in an alpine area

Z. H. He et al.

Title Page

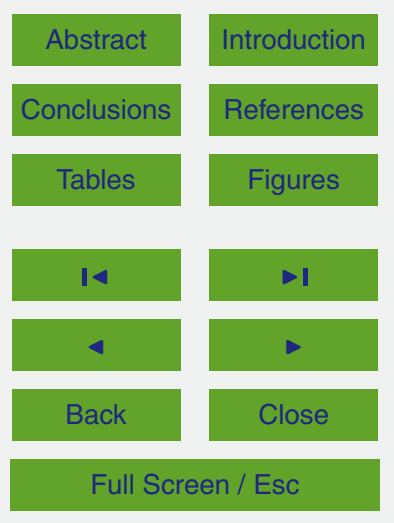

Printer-friendly Version

Interactive Discussion 
Table 4. Calibrated parameters by the stepwise and automatic methods.

\begin{tabular}{lll}
\hline Parameter & $\begin{array}{l}\text { Stepwise } \\
\text { calibrated }\end{array}$ & $\begin{array}{l}\text { Automatic } \\
\text { calibrated }\end{array}$ \\
\hline KKA & 1.1 & 5.6 \\
KKD & 0.002 & 99.1 \\
$D_{\mathrm{s}}\left(\mathrm{mm}^{\circ} \mathrm{C}^{-1} \mathrm{day}^{-1}\right)$ & 2.5 & 2.03 \\
$D_{\mathrm{g}}\left(\mathrm{mm}^{\circ} \mathrm{C}^{-1} \mathrm{day}^{-1}\right)$ & 7.2 & 7.52 \\
WM $(\mathrm{cm})$ & 10.5 & 11.9 \\
$B$ & 0.80 & 0.62 \\
\hline
\end{tabular}

HESSD

11, 13385-13441, 2014

Diagnostic

calibration of

a hydrological model

in an alpine area

Z. H. He et al.

Title Page

Abstract

Introduction

Conclusions

References

Tables

Figures

14

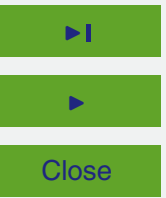

Back

Close

Full Screen / Esc

Printer-friendly Version

Interactive Discussion 
Table 5. Evaluation merits for the stepwise and automatic calibration methods.

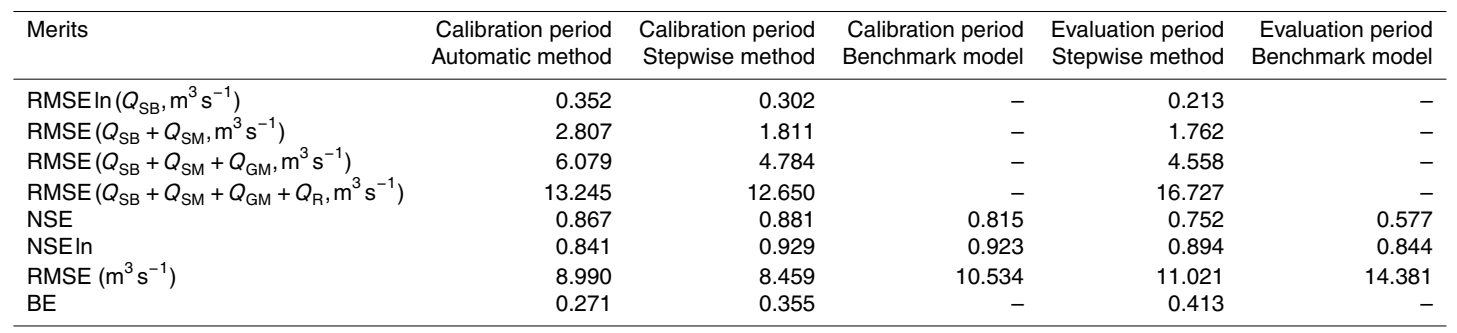

\section{Diagnostic} calibration of

a hydrological model in an alpine area

\section{Z. H. He et al.}

Title Page

Abstract

Conclusions

Introduction

Tables

References

Figures

14

Back

Close

Full Screen / Esc

Printer-friendly Version

Interactive Discussion 
Table 6. Sensitive analysis of the calibrated parameters on lowest elevation band for glacier area (LEG) and storm rain period (SRP). NSE is the Nash Sutcliffe Efficiency value for the calibration period.

\begin{tabular}{|c|c|c|c|c|c|c|c|c|}
\hline & LEG (a.s.I. m) & $D_{\mathrm{s}}\left(\mathrm{mmd}^{-1}{ }^{\circ} \mathrm{C}^{-1}\right)$ & 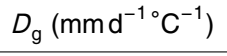 & WM $(\mathrm{cm})$ & $B$ & $\mathrm{KKA}$ & $\mathrm{KKD}$ & NSE \\
\hline SRP: & 3450 & 2.2 & 8.0 & 10.1 & 0.70 & 0.7 & 0.002 & 0.870 \\
\hline \multirow[t]{5}{*}{ May-Sep } & 3150 & 2.5 & 7.9 & 10.1 & 0.75 & 0.7 & 0.002 & 0.871 \\
\hline & 2950 & 2.5 & 7.2 & 10.5 & 0.80 & 1.1 & 0.002 & 0.881 \\
\hline & 2750 & 3.0 & 6.8 & 10.2 & 0.75 & 1.0 & 0.002 & 0.880 \\
\hline & 2450 & 2.8 & 5.8 & 10. & 0.78 & 0.8 & 0.002 & 0.876 \\
\hline & SRP & $D_{\mathrm{s}}\left(\mathrm{mm} \mathrm{d}^{-1}{ }^{\circ} \mathrm{C}^{-1}\right)$ & $D_{\mathrm{g}}\left(\mathrm{mmd}^{-1}{ }^{\circ} \mathrm{C}^{-1}\right)$ & WM $(\mathrm{cm})$ & $B$ & $\mathrm{KKA}$ & $\mathrm{KKD}$ & NSE \\
\hline \multirow[t]{5}{*}{ LEG $=2950 \mathrm{~m}$} & Jun-Aug & 2.9 & 7.5 & 8.2 & 0.75 & 0.9 & 0.002 & 0.871 \\
\hline & May-Oct & 2.8 & 6.9 & 9.4 & 0.76 & 0.8 & 0.002 & 0.882 \\
\hline & May-Sep & 2.5 & 7.2 & 10.5 & 0.80 & 1.1 & 0.002 & 0.881 \\
\hline & Apr-Sep & 2.2 & 7.1 & 8.3 & 0.75 & 0.9 & 0.002 & 0.878 \\
\hline & Apr-Oct & 2.6 & 6.9 & 9.4 & 0.77 & 1.1 & 0.002 & 0.881 \\
\hline
\end{tabular}

\section{HESSD}

$11,13385-13441,2014$

\section{Diagnostic}

calibration of

a hydrological model

in an alpine area

Z. H. He et al.

Title Page

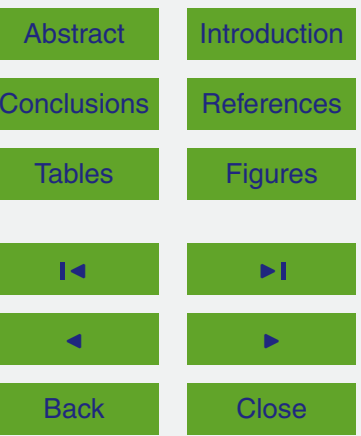

Full Screen / Esc

Printer-friendly Version

Interactive Discussion 
Table 7. $R_{\mathrm{MS}}(\%)$ for parameter sensitivity ( $R_{\mathrm{MS}}$ values indicating the most sensitive parameters are labeled in bold).

\begin{tabular}{lcrrrrrrrrrr}
\hline \multirow{2}{*}{ Merits } & \multicolumn{4}{c}{ Subsurface } & \multicolumn{1}{c}{ Routing } & \multicolumn{1}{c}{ Infiltration } & Interception & \multicolumn{2}{c}{ Rainfall Runoff } & \multicolumn{2}{c}{ Melt } \\
& $K_{\mathrm{s}}^{\mathrm{u}}$ & $K_{\mathrm{s}}^{\mathrm{s}}$ & $\mathrm{KKA}$ & $\mathrm{KKD}$ & $n^{t}$ & $\alpha^{\mathrm{IFL}}$ & $F \max ^{b}$ & WM & $B$ & $D_{\mathrm{s}}$ & $D_{\mathrm{g}}$ \\
\hline $\operatorname{RMSEln}\left(Q_{\mathrm{SB}}\right)$ & 9.70 & 11.14 & $\mathbf{3 8 . 4 4}$ & $\mathbf{4 4 . 3 9}$ & 15.70 & 0.12 & 0.08 & 1.07 & 18.51 & 7.53 & 2.88 \\
$\operatorname{RMSE}\left(Q_{\mathrm{SB}}+Q_{\mathrm{SM}}\right)$ & 0.32 & 0.40 & 11.91 & 0.06 & 9.35 & 0.47 & 0.14 & 8.27 & 25.14 & $\mathbf{5 1 . 2 2}$ & 0.69 \\
$\operatorname{RMSE}\left(Q_{\mathrm{SB}}+Q_{\mathrm{SM}}+Q_{\mathrm{GM}}\right)$ & 0.22 & 0.21 & 0.62 & 0.64 & 10.00 & 0.17 & 0.25 & 7.92 & 0.29 & 26.28 & $\mathbf{4 0 . 7 9}$ \\
$\operatorname{RMSE}\left(Q_{\mathrm{SB}}+Q_{\mathrm{SM}}+Q_{\mathrm{GM}}+Q_{\mathrm{R}}\right)$ & 0.17 & 0.85 & 0.57 & 0.97 & 1.84 & 0.08 & 0.06 & $\mathbf{1 9 . 3 5}$ & $\mathbf{2 2 . 4 8}$ & 10.78 & 11.57 \\
\hline
\end{tabular}

\section{Diagnostic} calibration of

a hydrological model in an alpine area

Z. H. He et al.

\section{Title Page}

Abstract

Introduction

Conclusions

References

Tables

Figures

14

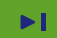

Back

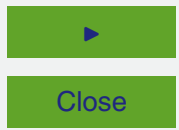

Full Screen / Esc

Printer-friendly Version

Interactive Discussion 


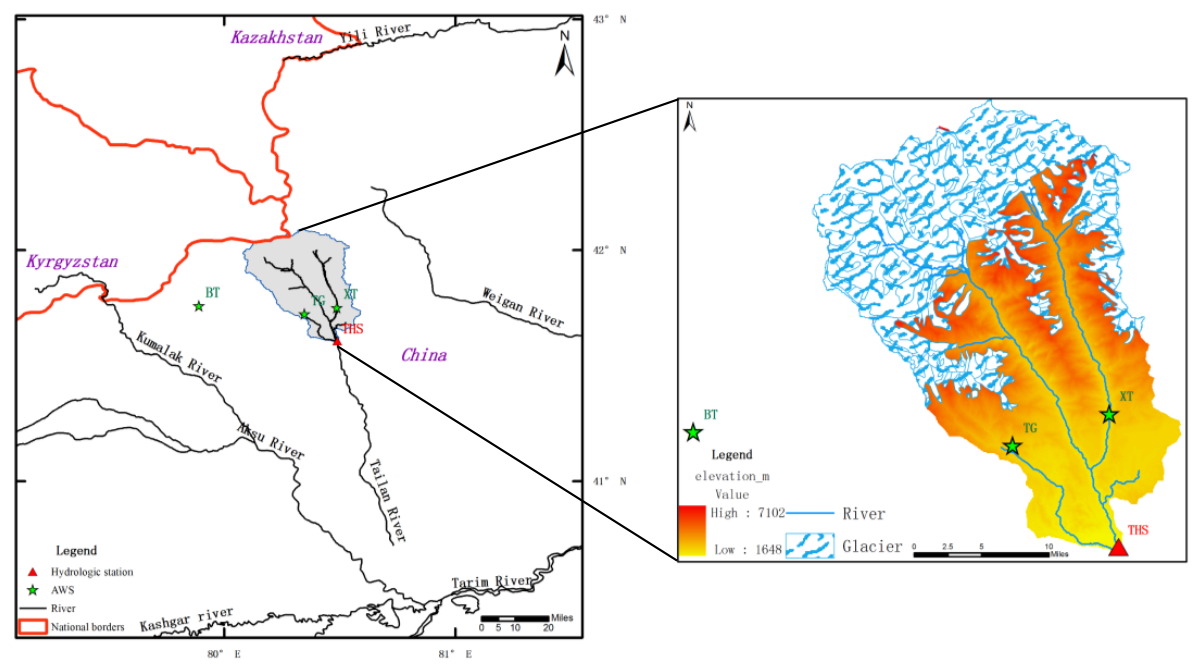

(a)

Figure 1. Location of the Tailan River basin in Xinjiang Uygur Autonomous Region, China. Two automatic weather stations (TG at 2381 ma.s.I. and XT at 2116 ma.s.l.) were set up in upstream mountain area in July 2011. Additionally, the BT weather station (3950 ma.s.l.) located in the adjacent Kumalak River basin was used to validate the estimated temperature lapse rates. The Tailan Hydrologic Station (THS) has gauged streamflow data at the catchment outlet since 1957 (a). Glacier occupies approximately $33 \%$ of the total basin area (b).

\section{HESSD}

$11,13385-13441,2014$

\section{Diagnostic \\ calibration of}

a hydrological model

in an alpine area

Z. H. He et al.

Title Page

Abstract

Introduction

Conclusions

References

Tables

Figures

14

4

Back

Close

Printer-friendly Version

Interactive Discussion 

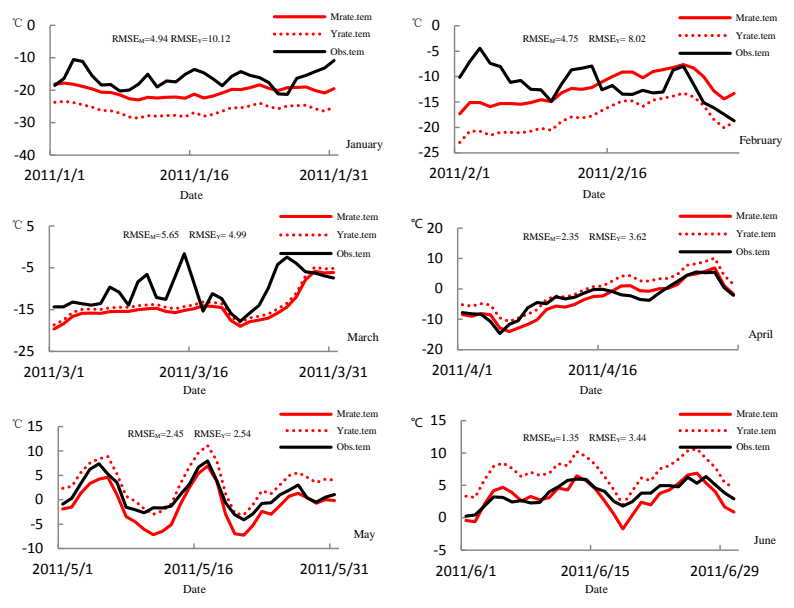

\section{HESSD}

$11,13385-13441,2014$
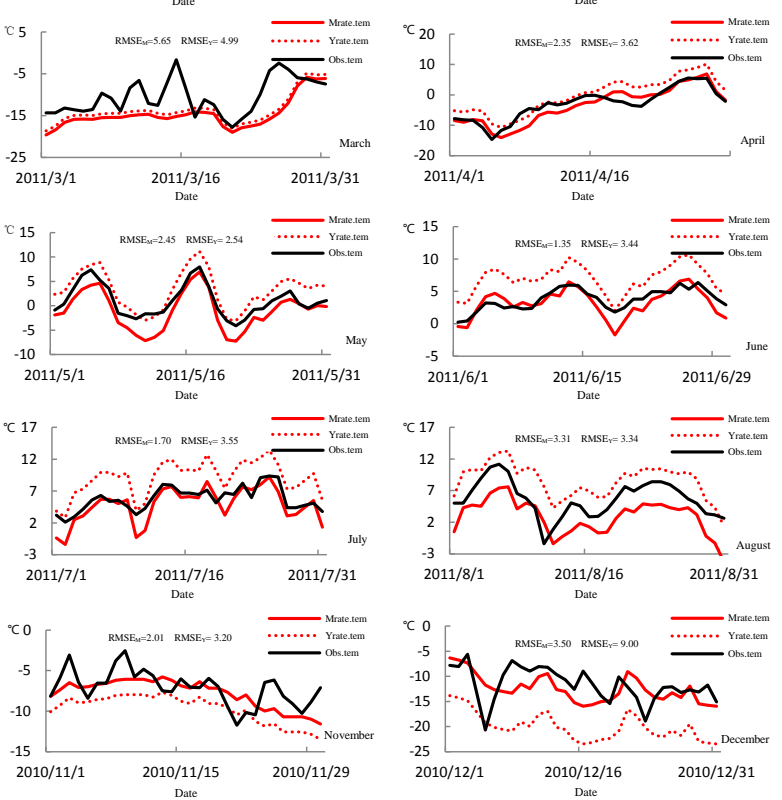

Figure 2. Evaluation of the estimated temperature lapse rate at the BT station. The black solid line is the observed temperature series at BT (Obs.tem); the red solid line is the estimated temperature by monthly lapse rate (Mrate.tem). The red dotted line indicates the estimated temperature based on annual constant rate (Yrate.tem). The goodness of fit between the observed and estimated temperature is measured by $R M S E_{M}$ for monthly lapse rate and $R M S E_{Y}$ for annual constant rate, respectively. The temperature series in September and October are absent at BT.

\section{Diagnostic}

calibration of

a hydrological model

in an alpine area

Z. H. He et al.

Title Page

Abstract

Introduction

Conclusions

References

Tables

Figures

14

Back

Close

\section{Full Screen / Esc}

Printer-friendly Version

Interactive Discussion 


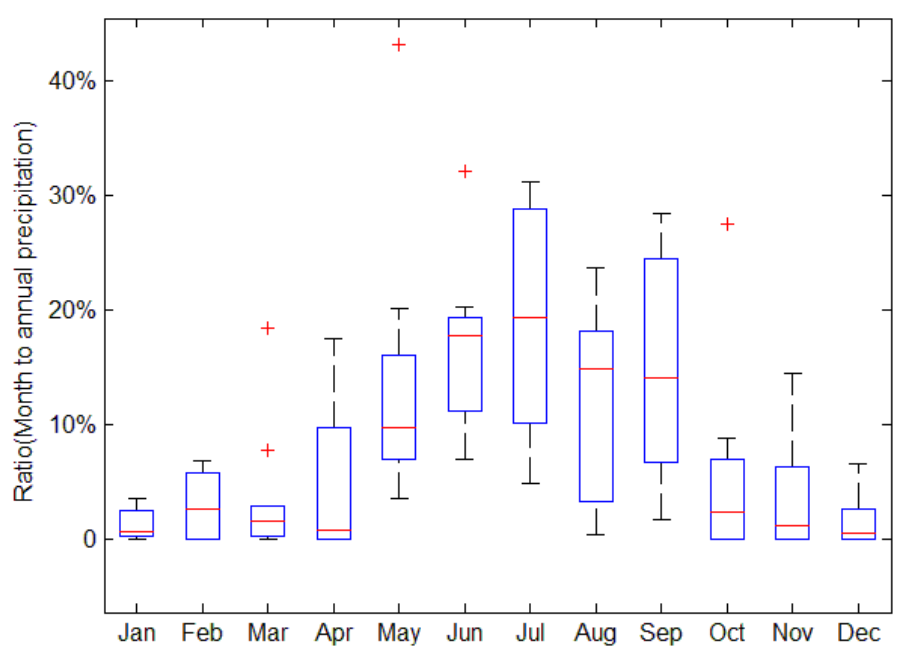

Figure 3. Proportion of monthly precipitation to annual amount (2003 2012). The red line in each box represents the median value for each month from 2003 to 2012. Red crosses indicate abnormal values that exceed 1.5 times the inter quartile range.

\section{HESSD}

$11,13385-13441,2014$

\section{Diagnostic}

calibration of

a hydrological model

in an alpine area

Z. H. He et al.

\section{Title Page}

Abstract

Introduction

Conclusions

References

Tables

Figures

14

Back

Close

Printer-friendly Version

Interactive Discussion 


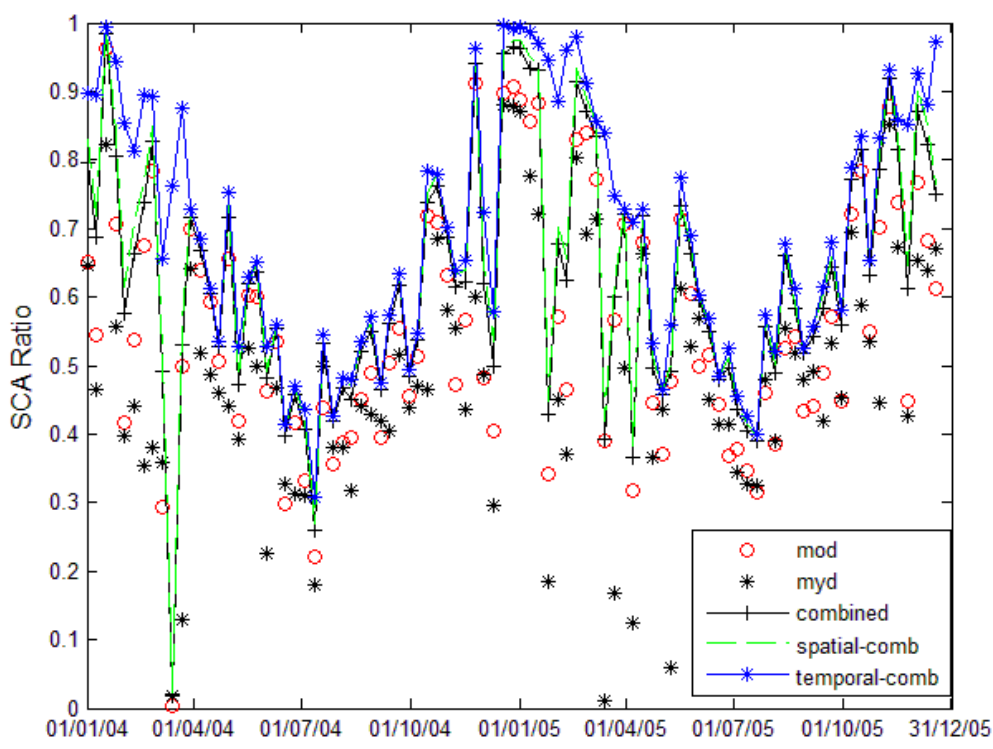

Figure 4. Filtered MODIS eight-day snow-cover products (2004-2005). The term "mod" is the snow cover area from MOD10A2 products, "myd" is MYD10A2 products, "combined" is the combined result from step1, "spatial-comb" from step2 and "temporal-comb" from step3. See Sect. 2.2.3 for details.

\section{HESSD}

$11,13385-13441,2014$

\section{Diagnostic \\ calibration of}

a hydrological model

in an alpine area

\section{Z. H. He et al.}

Title Page

Abstract

Introduction

Conclusions

References

Tables

Figures

14

$>1$

Back

Close

Printer-friendly Version

Interactive Discussion 


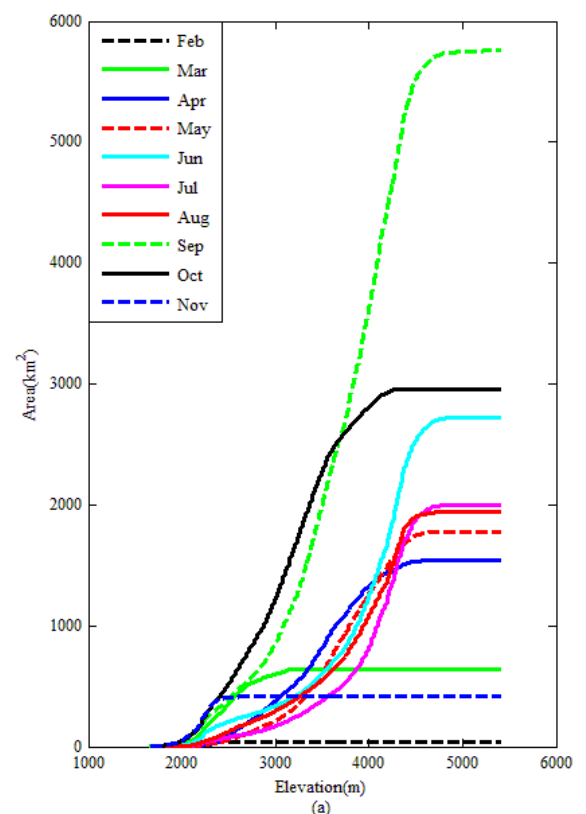

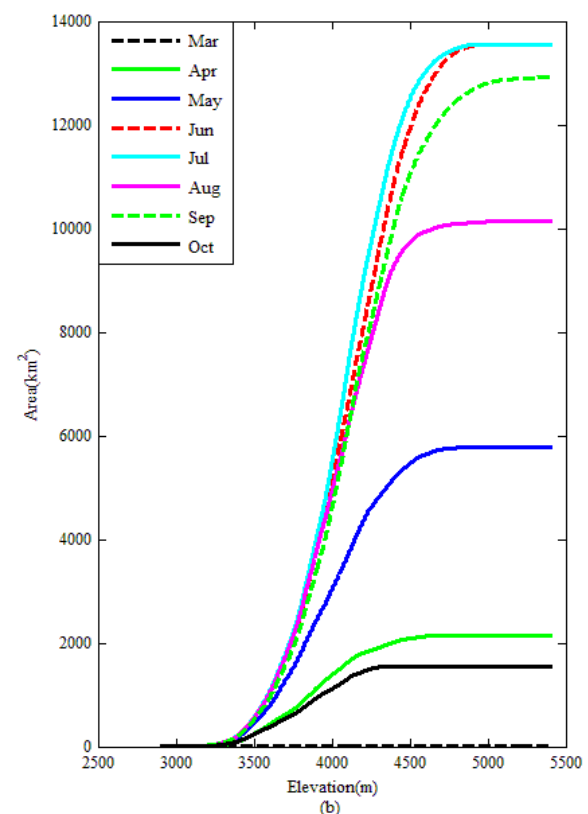

Figure 5. Altitudinal Cumulative Melt Curve. (a) Cumulative monthly snowmelt area distribution by elevation (2003 2012). (b) Cumulative monthly glacier melt area distribution by elevation (2003 2012). The snowmelt areas in December and January and the glacier melt areas in November, December, January and February are zero and are not shown in this figure.

\section{Diagnostic}

calibration of

a hydrological model

in an alpine area

Z. H. He et al.

Title Page

Abstract

Introduction

Conclusions

References

Tables

Figures

14

$>1$

4

Back

Close

Printer-friendly Version

Interactive Discussion

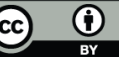




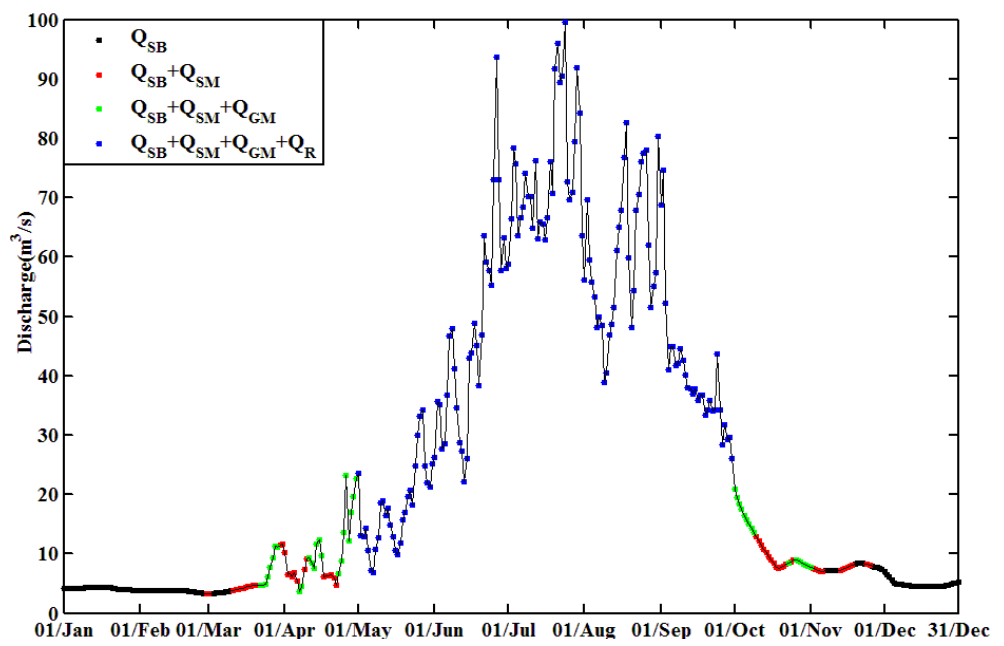

\section{HESSD}

$11,13385-13441,2014$

\section{Diagnostic \\ calibration of}

a hydrological model

in an alpine area

Z. H. He et al.

Title Page

Abstract

Introduction

Conclusions

References

Tables

Figures

14

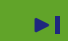

4

Figure 6. Hydrograph partition in 2003. $Q_{\mathrm{SB}}$ stands for subsurface baseflow generated by groundwater, $Q_{\mathrm{SM}}$ and $Q_{\mathrm{GM}}$ for snow meltwater and glacier meltwater respectively, and $Q_{\mathrm{R}}$ for rainwater directly runoff. 


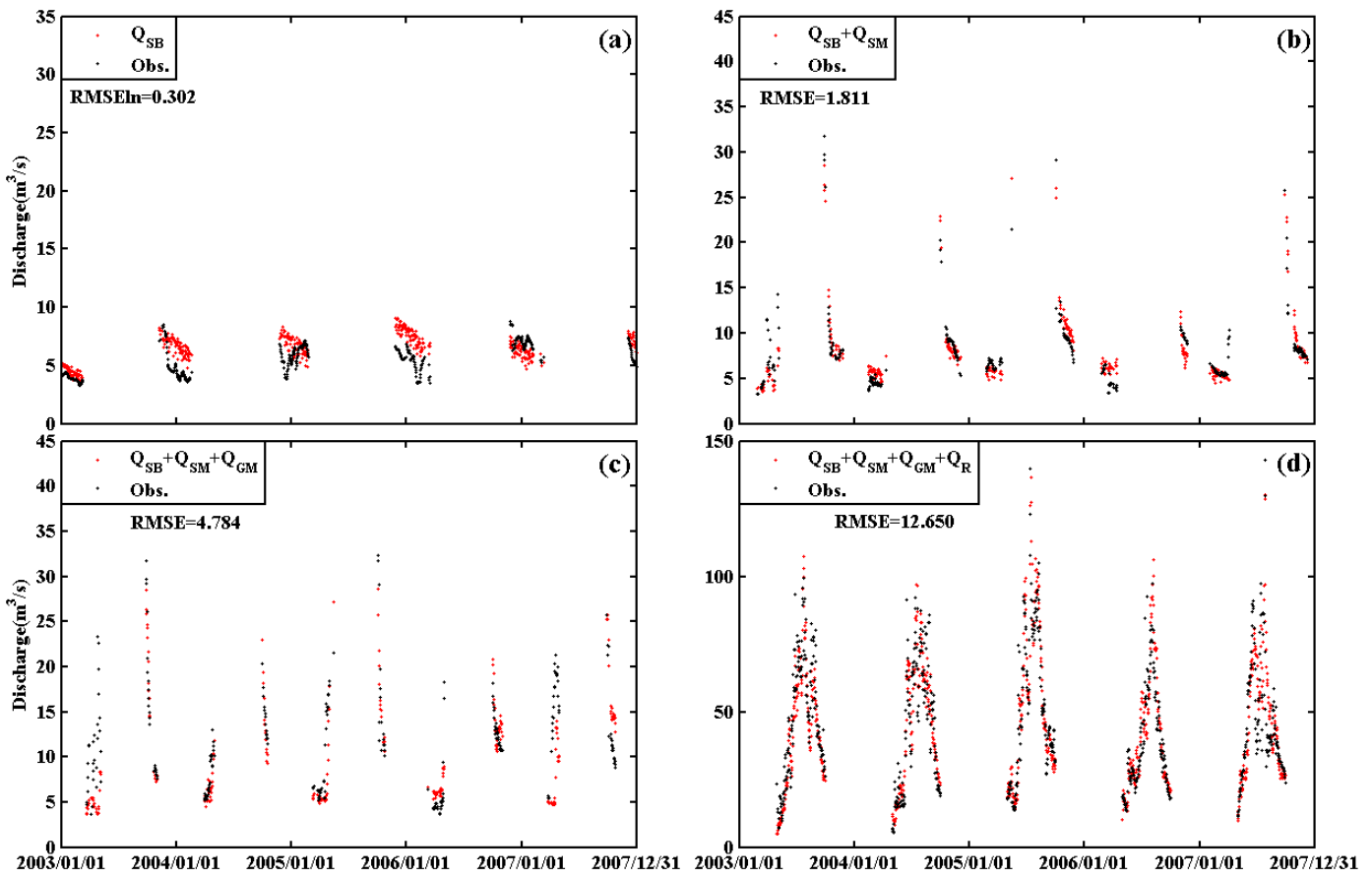

Figure 7. Stepwise calibration of grouped parameters upon partitioning curves. (a) Partitioning curves after calibrating KKA and KKD upon $Q_{\mathrm{SB}}$. (b) Partitioning curves after calibrating $D_{\mathrm{S}}$ upon $Q_{\mathrm{SB}}+Q_{\mathrm{SM}}$. (c) Partitioning curves after calibrating $D_{\mathrm{g}}$ upon $Q_{\mathrm{SB}}+Q_{\mathrm{SM}}+Q_{\mathrm{GM}}$. (d) Partitioning curves after calibrating $\mathrm{WM}$ and $B$ upon $Q_{\mathrm{SB}}+Q_{\mathrm{SM}}+Q_{\mathrm{GM}}+Q_{\mathrm{R}}$. The goodness of fit between observed and simulated discharge is measured by RMSEln (for $Q_{\mathrm{SB}}$ part) or RMSE (for other parts).

\section{HESSD}

$11,13385-13441,2014$

\section{Diagnostic}

calibration of

a hydrological model

in an alpine area

Z. H. He et al.

Title Page

Abstract

Introduction

Conclusions

References

Tables

Figures

14

$>1$

\section{4}

Back

Close

Printer-friendly Version

Interactive Discussion 

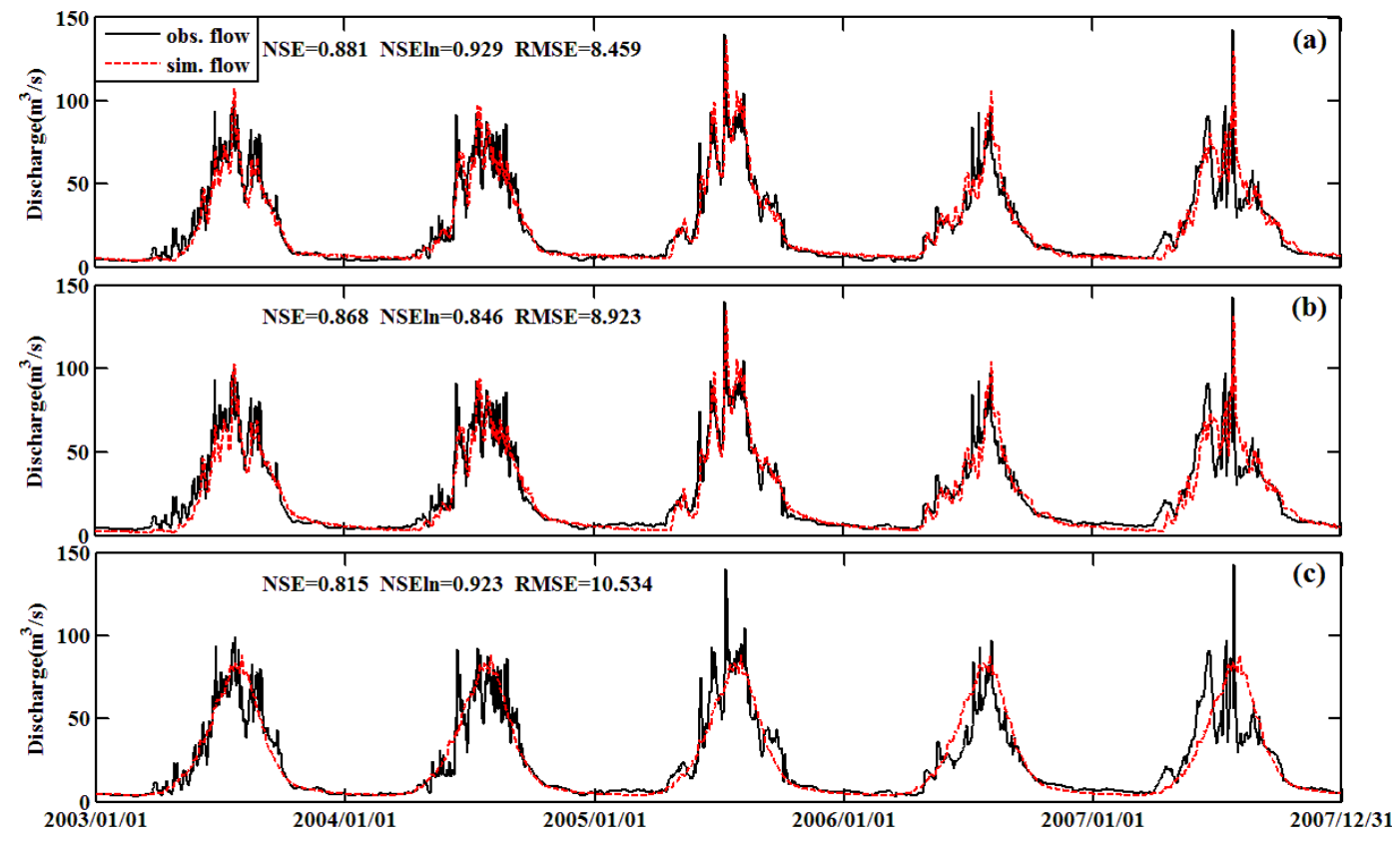

HESSD

11, 13385-13441, 2014

\section{Diagnostic \\ calibration of \\ a hydrological model \\ in an alpine area \\ Z. H. He et al.}

Title Page

Abstract

Introduction

Conclusions

References

Tables

Figures

14

$>1$

$\triangleleft$

Back

Close

Full Screen / Esc

proposed stepwise method, (b) by the automatic calibration method, and (c) by the benchmark model. The performance of the simulations is measured in NSE, NSEln and RMSE.

Printer-friendly Version

Interactive Discussion 


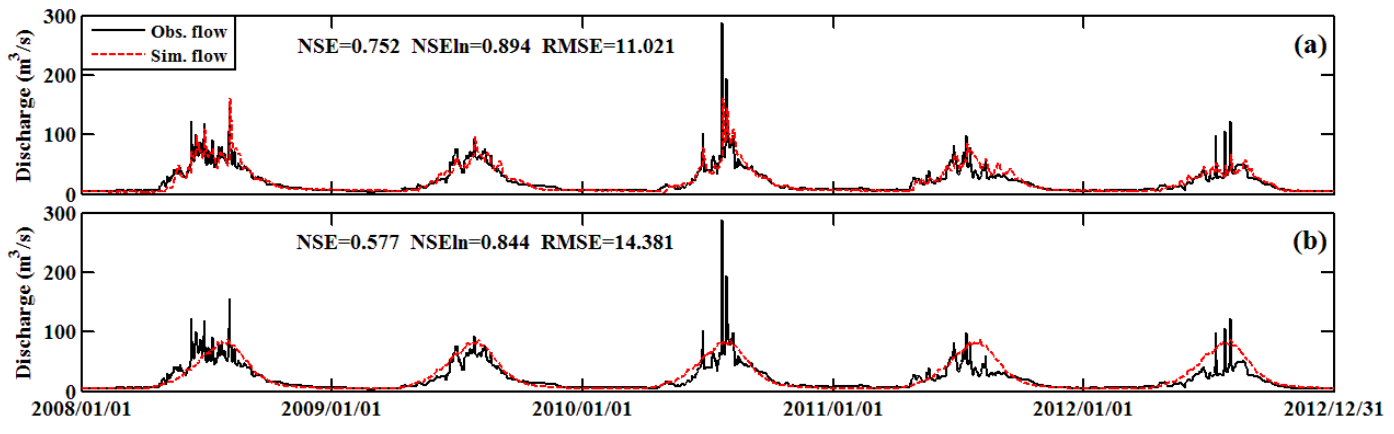

HESSD

$11,13385-13441,2014$

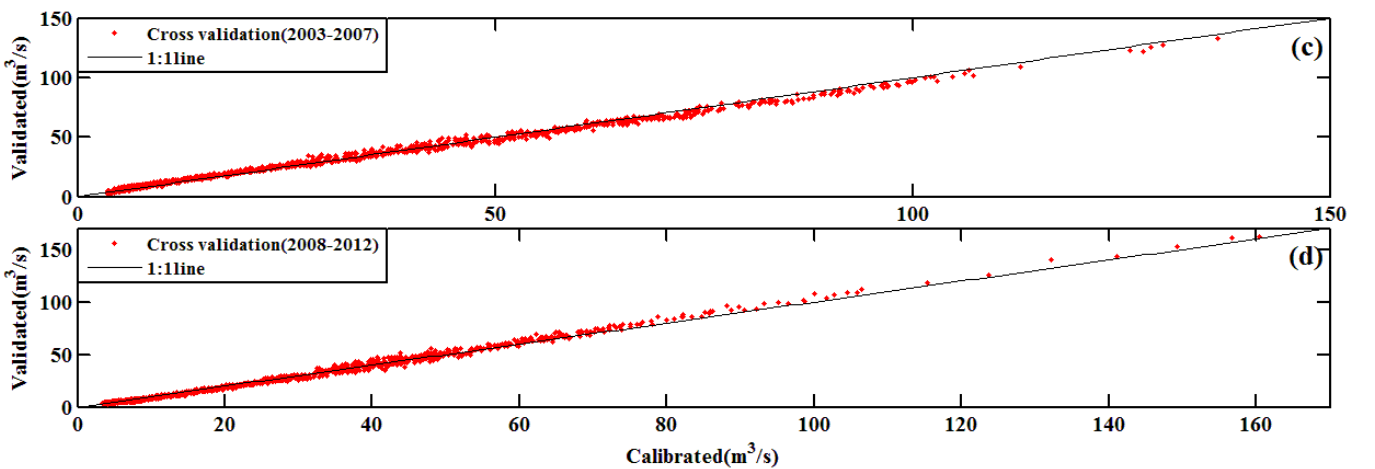

Figure 9. Evaluation of the stepwise calibration method. (a) Discharge simulation in evaluation period 2008 to 2012 using the stepwise calibrated parameters in calibration period 2003 to 2007. (b) Discharge simulation in evaluation period 2008 to 2012 by the benchmark model. (c) Cross validation simulation of daily discharge in 2003-2007. $x$ coordinate presents the simulated daily discharges by parameters calibrated in period 2003-2007. $y$ coordinate presents the simulated daily discharges by parameters calibrated in period 2008-2012. (d) Cross validation simulation of daily discharge in 2008-2012. $x$ coordinate presents the simulated daily discharges by parameters calibrated in period 2008-2012. $y$ coordinate presents the simulated daily discharges by parameters calibrated in period 2003-2007.

\section{Diagnostic}

calibration of

a hydrological model

in an alpine area

Z. H. He et al.

Title Page

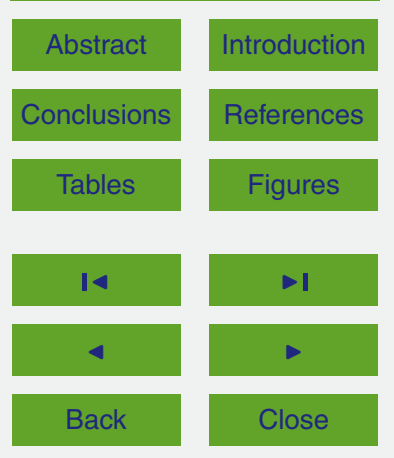

Full Screen / Esc

Printer-friendly Version

Interactive Discussion 

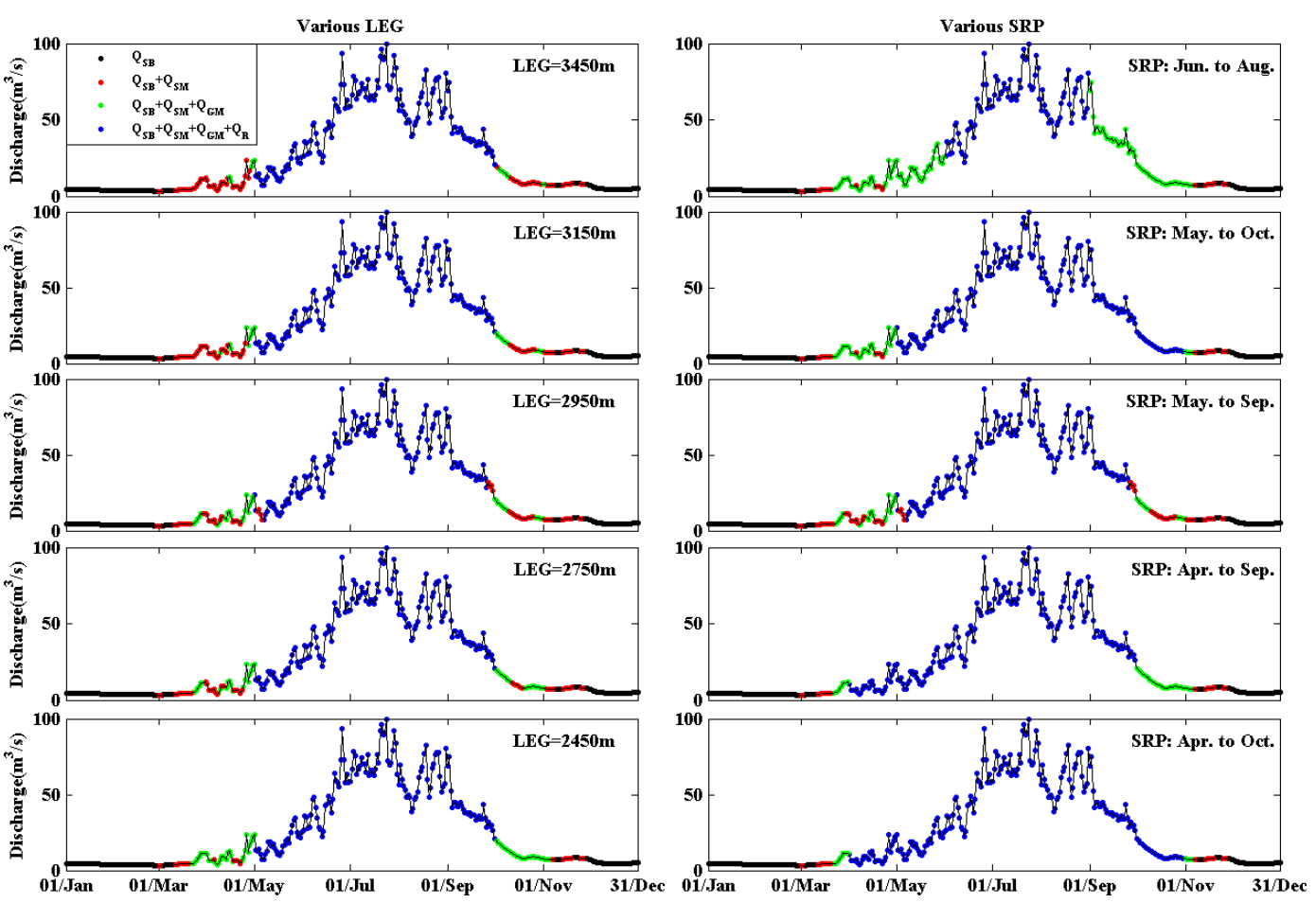

\section{HESSD}

11, 13385-13441, 2014

\section{Diagnostic \\ calibration of}

a hydrological model

in an alpine area

Z. H. He et al.

\section{Title Page}

Abstract

Introduction

Conclusions

References

Tables

Figures

14

।

4

Back

Close

Full Screen / Esc

Printer-friendly Version

Interactive Discussion

Figure 10. Sensitivity analysis for hydrograph partition. The first column is the hydrograph partition pattern using different lowest elevation band of the glacier area (LEG). The second column is the hydrograph partition pattern using different storm rain period (SRP). 

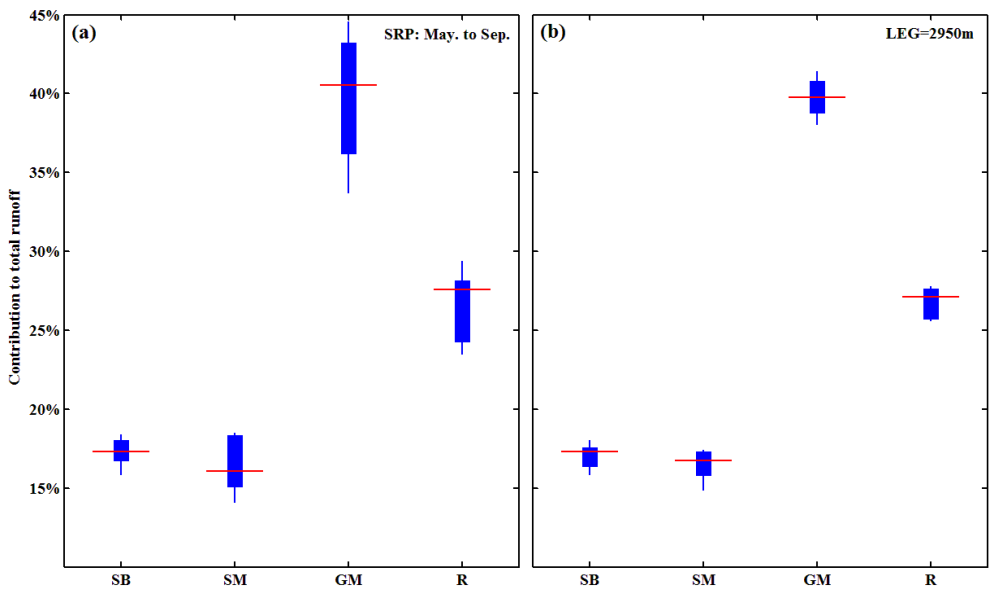

HESSD

11, 13385-13441, 2014

\section{Diagnostic \\ calibration of}

a hydrological model

in an alpine area

Z. H. He et al.

Title Page

Abstract

Introduction

Conclusions

References

Tables

Figures

Figure 11. Sensitivity analysis on the contributions of different runoff components to total runoff. (a) is the contribution pattern under different lowest elevation band of glacier area (LEG), where the storm rain period (SRP) is fixed as May to September. (b) is the contribution pattern under different SRPs, where the LEG is fixed as $2950 \mathrm{~m}$. The red line stands for the mean contribution for each runoff component, and the top/bottom end of each plot presents the highest/lowest contribution ratio. SB is groundwater baseflow, SM is snowmelt, GM is glacier melt and $R$ is rainwater directly runoff.

14

4

Back $\rightarrow$ I

$>$

Close

Full Screen / Esc

Printer-friendly Version

Interactive Discussion 